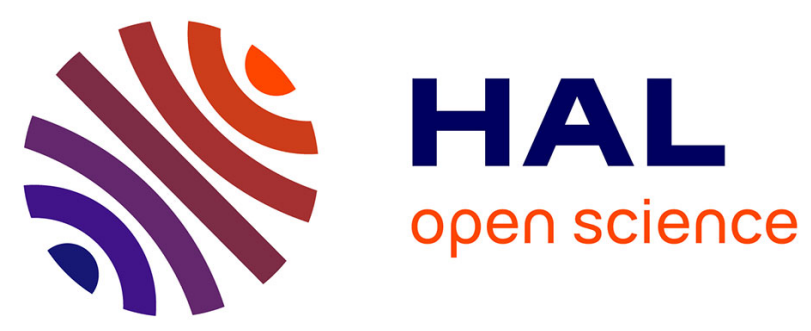

\title{
No evidence of Phago-mixotropy in Micromonas polaris (Mamiellophyceae), the Dominant Picophytoplankton Species in the Arctic
}

Valeria Jimenez, John A Burns, Florence Le Gall, Fabrice Not, Daniel Vaulot

\section{- To cite this version:}

Valeria Jimenez, John A Burns, Florence Le Gall, Fabrice Not, Daniel Vaulot. No evidence of Phagomixotropy in Micromonas polaris (Mamiellophyceae), the Dominant Picophytoplankton Species in the Arctic. Journal of Phycology, 2021, 57 (2), pp.435-446. 10.1111/jpy.13125 . hal-03267092

\section{HAL Id: hal-03267092 \\ https://hal.sorbonne-universite.fr/hal-03267092}

Submitted on 22 Jun 2021

HAL is a multi-disciplinary open access archive for the deposit and dissemination of scientific research documents, whether they are published or not. The documents may come from teaching and research institutions in France or abroad, or from public or private research centers.
L'archive ouverte pluridisciplinaire HAL, est destinée au dépôt et à la diffusion de documents scientifiques de niveau recherche, publiés ou non, émanant des établissements d'enseignement et de recherche français ou étrangers, des laboratoires publics ou privés. 


\section{No evidence of phago-mixotropy in Micromonas polaris, the dominant picophytoplankton species in the Arctic ${ }^{\dagger}$}

Valeria Jimenez ${ }^{1}$, John A. Burns ${ }^{2}$, Florence Le Gall ${ }^{1}$, Fabrice Not ${ }^{1,4}$, Daniel Vaulot ${ }^{1,3,5 *}$

${ }^{1}$ Sorbonne Université, CNRS, UMR7144, Ecology of Marine Plankton team, Station Biologique de Roscoff, 29680 Roscoff, France

${ }^{2}$ Bigelow Laboratory for Ocean Sciences, East Boothbay, ME, USA

${ }^{3}$ Asian School of the Environment, Nanyang Technological University, 50 Nanyang Avenue, Singapore 639798

${ }^{4}$ ORCID: 0000-0002-9342-195X

${ }^{5}$ ORCID: 0000-0002-0717-5685

*Corresponding author: vaulot@gmail.com

$\dagger$ This paper is dedicated to the memory of Hervé Moreau, who was coordinating this research project and passed away too young in July 2020.

keywords: phytoplankton, Arctic, phago-mixotrophy, Micromonas

Submitted to: Journal of Phycology

Date: November 26, 2020 


\begin{abstract}
In the Arctic Ocean, the small green alga Micromonas polaris dominates picophytoplankton during the summer months but is also present in winder. It has been previously hypothesized to be phago-mixotrophic (capable of bacteria ingestion) based on laboratory and field experiments. Prey uptake was analysed in several $M$. polaris strains isolated from different regions and depths of the Arctic Ocean and in Ochromonas triangulata, known to be a phagomixotroph, as a control. Using both fluorescent beads and fluorescently labelled bacteria as prey, we found no evidence of phago-mixotrophy in any $M$. polaris strain by flow cytometric measurement of prey ingestion in contrast to $O$. triangulata. In addition, in silico predictions revealed that members of the genus Micromonas lack a genetic signature of phagocytotic capacity.
\end{abstract}




\section{Introduction}

Polar regions are undergoing drastic changes due to climate change and global warming in particular. These changes have strong effects in Arctic marine ecosystems (Box et al. 2019, Graversen et al. 2008, Wassmann 2015) where phytoplankton production plays an essential role in food web dynamics and biogeochemical cycles (Arrigo et al. 2008, Kahru et al. 2016, Park et al. 2015). Considerable spatial and temporal changes in primary production have been observed in the last two decades (Kahru et al. 2016, Renaut et al. 2018, Tedesco et al. 2019). Rapid melting and early ice retreat increase the open areas exposed to solar radiation which in turns could result in an increase in annual net primary production along with a lengthening of the phytoplankton growing season (Kahru et al. 2016, Park et al. 2015, Renaut et al. 2018). Changes in Arctic primary production are also influenced by the increase of freshwater delivery to the upper ocean that leads to stronger water column stratification limiting the upward flux of nutrients to the surface (Brown et al. 2019, Coupel et al. 2015, Nummelin et al. 2016, Park et al. 2015, Slagstad et al. 2015, Timmermans et al. 2011, Tremblay et al. 2015).

Our ability to explain and predict the responses of Arctic phytoplankton communities to climate change is challenged by our limited understanding regarding their ecological and physiological strategies of growth and survival. Arctic phytoplankton communities experience extreme environmental conditions such as nutrient limitation, exposure to a long period of darkness (polar winter) followed by low light levels under the ice linked to snow coverage and ice thickness (Berge et al. 2015). In such unfavorable and shifting context, it has been suggested that phago-mixotrophy (ability to combine photosynthesis and bacterivory) could be a common trophic strategy among Arctic protists (Stoecker \& Lavrentyev 2018). At the scale of the global ocean, phago-mixotrophy is an important, but until recently underestimated, process for energy and nutrient transfer (e.g. carbon fluxes) throughout the food web (Caron 2016, Mitra et al. 2014, Ward \& Follows 2016). Phago-mixotrophic plankton are widespread in the ocean and evolutionary diverse, found in many branched of the eukaryotic tree (Selosse et al. 2017). They account for a large proportion of bacterivory in aquatic environments (Hartmann et al. 2012, Leles et al. 2019, Unrein et al. 2014). A recent study (Stoecker \& Lavrentyev 2018) reviews the current evidence and importance of phago-mixotrophy in the Arctic ocean where 
this trophic mode has been documented in chrysophytes (e.g. Ochromonas spp., Dinobryon balticum), cryptophytes (e.g. Geminigera cryophila, Teleaulax amphioxeia), prymnesiophytes (e.g. Chrysochromulina spp.), dinoflagellates (e.g. Heterocapsa triquetra, Tripos arcticus) as well as chlorophytes (e.g. Pyramimonas spp.).

The on-going expansion of stratification and nutrient limitation in the Arctic have been associated with an observed increase of the smaller picophytoplankton (Li et al. 2009, Ward 2015) which ranges $2-3 \mu \mathrm{m}$ in cell diameter and is composed essentially of eukaryotes since cyanobacteria are nearly absent in polar marine ecosystems (Paulsen et al. 2016). Among the picoeukaryotic phytoplankton community, the green alga M. polaris (Lovejoy et al. 2007, Simon et al. 2017) dominates in the Arctic ocean in the summer months (Balzano et al. 2012, Kilias et al. 2014, Lovejoy et al. 2007, Marquardt et al. 2016) but is also present throughout the winter (Joli et al. 2017). Its abundance is expected to increase as the stratified oligotrophic areas expand (Benner et al. 2020, Hoppe et al. 2018, Li et al. 2009). The physiological plasticity allowing $M$. polaris to dominate the Arctic picoeukaryote community is not yet well understood. M. polaris was shown in the laboratory, to positively respond to a combination of temperature increase and acidification by higher growth rate and biomass production (Hoppe et al. 2018). Phago-mixotrophy would be another advantageous trait that could contribute to the success of $M$. polaris in the Arctic. Under prolonged periods of darkness or low irradiance, phago-mixotrophs could survive, despite reduced or even null rates of photosynthesis, by supplementing their carbon requirements through phagocytosis (Millette et al. 2017, Stoecker \& Lavrentyev 2018, Zhang et al. 1998). Under oligotrophic conditions, phago-mixotrophy could also supply the cell with limiting nutrients (Stoecker et al. 2017).

Evidence of phago-mixotrophy in Micromonas has been previously obtained in laboratory and field experiments (González et al. 1993, McKie-Krisberg \& Sanders 2014, McKie-Krisberg et al. 2018, Sanders \& Gast 2012). More than 25 years ago, González et al. (1993) reported phago-mixotrophy in a temperate Micromonas strain (identified at that time as M. pusilla) based on a positive acid lysozyme assay and ingestion of fluorescently labelled bacteria (FLBs) measured by microscopy. More recently, the ability of Arctic pico and nanoplankton microbial communities to consume bacterioplankton has been analyzed by in situ experiments using FLBs and 
yellow-green fluorescent microspheres (YG-beads) as prey. A Micromonas-like picoeukaryote, based on its shape and analysis of denaturing gradient gel electrophoresis (DGGE) band sequences, was reported to ingest a significant quantity of prey offered to it (Sanders \& Gast 2012). Ingestion of beads was further tested in M. polaris strain CCMP2099 under laboratory conditions that compared different light levels and nutrient concentrations. The highest grazing rates were observed under light and low nutrient conditions (McKie-Krisberg \& Sanders 2014) for which transcriptional response was also investigated (McKie-Krisberg et al. 2018). Despite the evidence presented, it is still unclear whether $M$. polaris is capable of ingesting bacteria because of the difficulty to distinguish whether the prey are inside the cells or just externally attached to them (Wilken et al. 2019) when using epifluorescence microscopy. Recently, association of YG-beads with $M$. polaris (strain CCMP2099) cells was found after performing feeding experiments with heat-killed cultures (Wilken et al. 2019), suggesting that beads may stick to the surface of the cells resulting in a potential over-estimation of phagocytosis.

In the present paper, we used flow cytometry to analyse prey uptake in several M. polaris strains isolated from different regions and depths in the Arctic Ocean, including CCMP2099 using the chrysophyte Ochromonas triangulata which is phago-mixotroph (Andersen et al. 2017) as a positive control. We also made predictions of the capacity of Micromonas to be a phago-mixotroph from an in silico gene-based model. 


\section{Materials and Methods}

\section{Strains and culturing conditions}

Four M. polaris strains and one phago-mixotrophic Ochromonas triangulata strain were used in this study. Three of the M. polaris strains (RCC2306, RCC4298 and RCC2258) and $O$. triangulata strain RCC21 (previously known as O. distigma, Andersen et al. 2017) were obtained from the Roscoff Culture Collection (RCC, http://www.roscoff-culture-collection.org). The fourth M. polaris strain (CCMP2099) was obtained from the Provasoli-Guillard National Center for Culture of Marine Phytoplankton and Microbiota (https://ncma.bigelow.org) and is also available from the RCC as RCC807. The M. polaris strains originate from different locations and depths in the Arctic (Table 1). All strains were non-axenic and grown under a 12h:12h light:dark cycle at $80 \mu \mathrm{mol}$ photons $\mathrm{m}^{-2} \mathrm{~s}^{-1}$ PAR using L1 medium (Guillard \& Hargraves 1993) made with artificial sea water (ASW, salinity 35) (Keller et al. 1987). All M. polaris strains were grown at $4{ }^{\circ} \mathrm{C}$ and $O$. triangulata at $20{ }^{\circ} \mathrm{C}$. Cells were acclimated and maintained in mid-exponential growth phase before the beginning of each experiment.

\section{Cell monitoring, feeding estimates and sample fixation}

Cells and prey were counted using a Guava easyCyte (Luminex Corporation, USA) flow cytometer (FCM) equipped with a $488 \mathrm{~nm}$ laser recording cell counts, forward and side angle light scatters (FALS and SSC), both proxies of cell size, green (525 $\pm 30 \mathrm{~nm}$ band pass filter) and red $(695 \pm 50 \mathrm{~nm}$ band pass filter) fluorescences. Cultures under the different experimental conditions were monitored live using red autofluorescence from chlorophyll as a threshold. Flow cytometry was also used to determine the percent of cells with prey (YG-beads and FLBs) in samples fixed using a protocol modified from Sherr \& Sherr (1993) (acid Lugol's iodine solution and formaldehyde $3.7 \%$, and cleared with sodium thiosulfate $3 \%$ ) with a threshold either on red fluorescence or green fluorescence. With the threshold on red fluorescence, cells that contained chlorophyll as well as green fluorescence (same signal as the prey added, YG-beads or FLBs) were considered to be cells containing prey (Figure S1). In addition, to confirm the total concentration of prey added to each flask, the sample was also run with the threshold on green fluorescence. FCM listmodes were analyzed with the Guava easyCyte Suite Software 3.1 
(Luminex Corporation, USA).

For each feeding experiment, the ingestion of prey was quantified in each experimental flask by first adding prey and then sub-sampling and fixing after an incubation of $0\left(\mathrm{~T}_{0}\right), 20\left(\mathrm{~T}_{20}\right)$ and $40\left(\mathrm{~T}_{40}\right)$ minutes. The $\mathrm{T}_{0}$ sample accounts for the physical attachment of prey to the cell and therefore the percent of cells ingesting prey corresponds to the percent of cells with prey at $\mathrm{T}_{20}$ or $\mathrm{T}_{40}$, minus the percent of cells with prey at $\mathrm{T}_{0}$.

\section{Microscopy}

Light-limited M. polaris (strain RCC2306) cells were fixed just after the addition of YG-beads $\left(\mathrm{T}_{0}\right)$ with glutaraldehyde (1\% final concentration). Fixed cells were sedimented onto formvar coated copper grids for 30 minutes. Grids were then stained with three drops of uranyl acetate 2\%, dried and examined using a JEOL JEM1400 transmission electron microscopy (TEM, Jeol, Tokyo, Japan) operating at $80 \mathrm{kV}$. Images were obtained with a Gatan Orius camera (Roper Scientific SAS, France).

\section{Major feeding experiments}

To test feeding, three different experimental designs were performed with $M$. polaris strains and another fourth with $O$. triangulata (Table 2). Feeding was primarily tested using yellow-green fluorescent polystyrene-based microspheres (YG-beads, diameter $0.5 \mu \mathrm{m}$, Fluoresbrite, Polysciences, Inc., Warrington, PA, USA) as prey. In some experiments fluorescently labelled bacteria (FLBs) were used. FLBs were prepared according to the protocol of Sherr et al. (Sherr et al. 1987) using the bacteria Brevundimonas diminuta (strain CECT313, also named Pseudomonas diminuta), obtained from the Spanish Type Culture Collection (CECT, Valencia, Spain).

In experiment type 1 (M. polaris-EXP1) feeding was tested for each $M$. polaris strain grown under four different culture conditions. Each treatment was carried out (in duplicates for RCC2306 and RCC4298 and triplicates for RCC2258 and CCMP2099) by transferring a small volume of culture (a few $\mathrm{ml}$ in general), previously maintained in mid-exponential growth, to about $40 \mathrm{ml}$ of L1-ASW medium (replete) or ASW without any addition (limited) in a 50 $\mathrm{ml}$ culture flask and then placed in the dark or left in the same light conditions as for culture 
maintenance. Each treatment (light-replete, light-limited, dark-replete and dark-limited) was followed up for 15-17 days and feeding was tested with YG-beads after 7 (Feeding 1) and 14-17 (Feeding 2) days.

Experiment type 2 (M. polaris-EXP2) was performed with M. polaris strain RCC2306 and RCC2258 and was set-up the same way as EXP1 (in triplicates), but with an additional treatment (light-replete-Ab) in which $1 \mu \mathrm{l}$ of Penicillin-Streptomycin-Neomycin (PSN) antibiotics solution (Sigma Aldrich P4083) was added per ml of culture at the beginning of the experiment in order to minimize bacteria concentration. Moreover, the five treatments were incubated for only one week and feeding was tested with YG-beads at the end of the incubation (Day 7).

To compare feeding on YG-beads vs. FLBs, a third type of experiment (M. polaris-EXP3) was performed with M. polaris RCC4298. For each prey type (YG-beads and FLBs) feeding was tested in triplicate in mid-exponential phase cultures (light-replete).

For all experiments (M. polaris-EXP1 to EXP3), the initial concentration for each treatment was $5 \times 10^{5}$ cells $\mathrm{ml}^{-1}$. The prey concentration was adjusted in order to achieve a prey to cell ratio of 1.5 to 2.5 .

The experimental design of experiments EXP1 and 2 performed with $O$. triangulata was the same and only differed in their replication and number of feeding time points. O. triangulataEXP1 was conducted in duplicate and with three feeding time points $\left(\mathrm{T}_{0}, \mathrm{~T}_{20}\right.$ and $\left.\mathrm{T}_{40}\right)$, and $O$. triangulata-EXP2 in triplicates and two feeding time points $\left(\mathrm{T}_{0}\right.$ and $\left.\mathrm{T}_{40}\right)$. Feeding was tested under two different culture conditions by transferring a small volume of culture, previously maintained in mid-exponential growth, to L1-ASW medium (light-replete) or ASW without any addition (light-limited) and incubated in the same light conditions as for culture maintenance. After one week of incubation, feeding was tested with YG-beads. The third experiment type (O. triangulata-EXP3) was performed in parallel with $M$. polaris-EXP3 to compare feeding on YG-beads and FLBs. For each prey type (YG-beads and FLBs) feeding was tested in biological triplicates in mid-exponential phase cultures (light-replete). In a fourth experiment type $(O$. triangulata-EXP4) feeding was tested using FLBs as prey in light-replete culture conditions. EXP4 was performed two times (EXP4a and b) and each time in duplicates. 


\section{Additional experiments}

The degree of attachment of YG-beads to cells, immediately after the addition of prey $\left(\mathrm{T}_{0}\right)$ was further examined in a number of additional experiments (M. polaris-EXP5) performed with M. polaris strains RCC2306 and RCC4298. For M. polaris strain RCC2306 the quantification was done in cultures grown under light-replete, light-limited, dark-replete and dark-limited conditions, and for M. polaris strain RCC4298 with cultures grown under these four conditions plus light-replete-Ab.

The effects of fixation on the attachment of YG-beads to cells (M. polaris-EXP6) was measured by simultaneously comparing feeding in experiments performed with $M$. polaris (strain RCC2306) and run in the flow cytometer live or after fixation with Lugol's iodine solution and glutaraldehyde ( $0.25 \%$ final concentration). For this experiment, M. polaris (strain RCC2306) in mid-exponential (Light-replete) feeding was measured at two time points $\left(\mathrm{T}_{0}\right.$ and $\left.\mathrm{T}_{40}\right)$.

Feeding on three different YG-bead sizes $(0.5,1$, and $2 \mu \mathrm{m}$ in diameter) (M. polaris-EXP7) was measured in M. polaris (strain RCC2306) incubated for one week in light-limited conditions (duplicates). Feeding was measured independently for each bead size using two feeding time points $\left(\mathrm{T}_{0}\right.$ and $\left.\mathrm{T}_{40}\right)$.

Changes in the number of cells with YG-beads was measured by continuously running a live sample for 20 minutes immediately after the addition of YG-beads (M. polaris-EXP8). Samples were quantified on the FACSCanto (BD Biosciences, USA) flow cytometer with the same configuration as the Guava. For this experiment, cultures of M. polaris (strain RCC2306), previously incubated for one week in light-limited conditions, were used. Two ratios of beads to cells were tested (ratio of 1:1 and 2:1) in duplicates.

The percent of cells potentially containing food vacuoles (EXP9) was quantified in M. polaris (strain RCC2306) and O. triangulata, stained with the probe LysoSensor Green DND-189 (Thermo Fisher Scientific), that accumulates in acid cellular compartments like food vacuoles, at a final concentration of $1 \mu \mathrm{M}$. After the addition of Lysosensor, cells were incubated in the dark for 8 minutes and measured for 2 minutes using the Guava easyCyte (Luminex Corporation, USA) flow cytometer (triggered on green fluorescence). Cells with higher green fluorescence, after incubation with Lysosensor, were considered as potentially containing food vac- 
uoles (Figure S2). The cells used for this test came from light-limited cultures (duplicates), from O. triangulata-EXP1 and M. polaris-EXP2, on which feeding experiments were performed.

\section{Data analysis}

Data processing, graphics and statistical analyses were performed using the R software (R Core Team 2014) using in particular the package set tidyverse. Pairwise comparisons were performed with the t.test function to calculate p-values based on Student (assuming equal variances) and Welch (assuming unequal variances) t-test.

\section{Trophic mode predictions from genome and transcriptome analysis}

Predicted peptides from whole genome (van Baren et al. 2016, Worden et al. 2009) or transcriptome data (Keeling et al. 2014) were downloaded from publicly available databases as detailed in Table S1. Because computational predictions are based on presence/absence information, predicted peptides from independent transcriptome assemblies of the same strain were concatenated to include as much information about each strain as possible. Computational prediction of phagocytotic, photosynthetic, and prototrophic capabilities were completed as in Burns et al. (2018a). This involved scoring a set of 14,095 protein profile hidden Markov models (HMMs) that were derived by clustering all proteins in 35 reference eukaryote genomes of known trophic mode against all proteins from each test genome or transcriptome. HMM profiles with a full sequence e-value $\leq 10^{-5}$ and a single domain e-value $\leq 10^{-4}$ to any protein in a test genome or transcriptome were marked as "present" for that organism. Predictive models of trophic modes were built by grouping the reference eukaryotes by known trophic mode and discovering HMMs from the set of 14,095 proteins that had differential presence/absence patterns between groups. Those HMMs whose presence/absence patterns differed according to trophic mode were annotated against SwissProt and grouped by gene ontology (GO) terms. GO categories were scored per reference organism and a best predictive set of GO terms was selected for each trophic mode using machine learning algorithms, forming the core of the predictive trophic mode models. Each test genome/transcriptome was scored for the predictive GO categories of the trophic mode models using its HMM presence/absence vector. Final prediction probabil- 
ities for each test genome/transcriptome were calculated against the reference trophic mode models using a probability neural network. To visualize the prediction output, which exists in four dimensions with three degrees of freedom (phagocytosis, photosynthesis, prototrophy, and a fourth dependent dimension for absence of each trophic mode), predictions were normalized such that the sum of the three predictions plus the probability of not fitting each trophic mode equaled 1 using the relation: $1-\left(p_{\text {phago }}+p_{\text {proto }}+p_{\text {photo }}\right) / 3$. The fractional independent probabilities of each trophic mode and the dependent absence number were mapped to 4-dimensional color space and projected onto a circle using scripts adapted from the R package "pavo" (Maia et al. 2013). Scripts are available at https://github.com/burnsajohn/predictTrophicMode. 


\section{Results}

\section{Feeding experiments}

M. polaris feeding was analyzed in four strains (CCMP2099, RCC2306, RCC4298 and RCC2258, Table 1) using a slight modification of the protocol described in Sherr \& Sherr (1993). We determined the percentage of cells feeding on YG-beads or FLBs using flow cytometry to quantify the proportion of cells with prey. Compared to epifluorescence microscopy, which is low throughput allowing examination of at most 100 to 200 cells per sample (e.g. McKie-Krisberg \& Sanders 2014), flow cytometry allows screening of a large number of cells per sample (typically several thousand). It also circumvents ambiguities that arise with microscopy when cells and prey randomly overlap during the filtration process (Wilken et al. 2019). To validate our approach we used the phago-mixotrophic O. triangulata strain RCC21 as a positive control. A range of experiments were performed to test different parameter combinations (Table 2).

M. polaris strains were grown under a combination of 2 light regimes and 2 nutrient concentrations (M. polaris-EXP1: light-nutrient replete, light-nutrient limited, dark-nutrient replete and dark-nutrient limited). Experiments took place over a period of 15 to 17 days. Feeding was examined with YG-beads after 7 (Feeding 1) and 14-17 days (Feeding 2). Clear negative growth effects under darkness and nutrient limitation conditions were observed for all strains. Overall, for all 4 strains under dark conditions, growth ceased between day 4 and day 7 and thereafter cell concentration remained stable (Figure 1). For cultures grown under low nutrient conditions (nutrient-limited), a decrease in growth rate was observed after one week (Figure 1). Additional signs of the effect of darkness and nutrient limitation were observed in FALS (proxy of cell size) and chlorophyll fluorescence: for example FALS decreased for cells in the dark (Figure S3). In all feeding experiments we observed that cells at time $\mathrm{T}_{0}$, immediately following addition of the beads, already had a number of beads associated with them. However, no significant difference was observed between the percent of cells with YG-beads at $T_{0} v s . T_{20}$ or $\mathrm{T}_{40}$ whatever the growth phase or the culture condition (Figures 2A and S4, Table S2).

We questioned whether the absence of feeding on YG-beads could have been due to the presence of bacteria in the cultures. In order to address this issue, we performed a second series 
of experiments in which we included a fifth condition by adding antibiotics to a light-nutrient replete culture (M. polaris-EXP2). This was only performed with two of the $M$. polaris strains (RCC2258 and RCC2306) and a single feeding experiment was conducted after one week. No feeding was detected under any of the culture conditions (Figure S5).

We then compared feeding on YG-beads vs. FLBs as prey (M. polaris-EXP3) since the prey type may influence feeding behavior. Again no feeding was observed when using either YGbeads or FLBs (Figure 2B). In contrast, in the four experiments performed with $O$. triangulata (EXP1 to EXP4) we observed feeding on YG-beads and FLBs that ranged from 7 to 14 and 21 to 27 percent of cells feeding on each prey type respectively, suggesting that Ochromonas clearly preferred FLBs over YG-beads ((Figure 2B, Table S2).

The percentage of cells with $0.5 \mu \mathrm{m}$ YG-beads at $\mathrm{T}_{0}$ was linearly related to bead concentration (Figure $\left.3, \mathrm{R}^{2}=0.93\right)$. Cell size did not seem to have an influence since Micromonas $(\simeq$ $1.5 \mu \mathrm{m})$ and Ochromonas $(\simeq 5 \mu \mathrm{m})$ fitted the same curve (Figure 3$)$. The number of cells with YG-beads did not change over time as demonstrated by monitoring live cells of $M$. polaris (strain RCC2306) in the presence of YG-beads by flow cytometry over a 20 minutes period (Figure S6).

The association of beads and cells did not seem to be linked to bead size. We still observed association of 1 and $2 \mu \mathrm{m}$ YG-beads with cells at $\mathrm{T}_{0}$, even though the $2 \mu \mathrm{m}$ beads are close in size to $M$. polaris cells and no differences were observed between the percent of cells with YGbeads at $\mathrm{T}_{0}$ and $\mathrm{T}_{40}$ (Figure $\mathrm{S} 7$ and Table $\mathrm{S} 3$ ). Fixation does not seem to impact the association of beads at $\mathrm{T}_{0}$ as we observed this co-association when samples were run live or fixed with Lugol's solution or glutaraldehyde (Table S4). External attachment of YG-beads to cells of $M$. polaris (strain RCC2306) was visualized by TEM (Figure S8).

Since the observation of acidic food vacuoles has been proposed as an evidence of phagotrophy (Carvalho \& Graneli 2006, Wilken et al. 2019), light-nutrient limited cultures of M. polaris (from EXP-2, which did not feed on YG-beads) were stained with the acidotropic LysoSensor fluorescent probe. No significant difference was observed in green LysoSensor fluorescence between unstained and stained cells, whereas for $O$. triangulata (EXP1 light-nutrient limited) green fluorescence increased 3.5 times after staining, suggesting the presence of food vacuoles 
in the latter species (Figure S2 and Table S5).

\section{Trophic mode predictions}

Phagocytotic, photosynthetic, and prototrophic capacity of protists can be predicted based on their genome or transcriptome composition (Burns et al. 2018a). We used this approach to analyze gene composition of a number of microalgae including Micromonas (Table S1). The predictions confirm that known phago-mixotrophs like Dinobryon sp., Pedinelalles sp., O. triangulata, and Prymnesium parvum have and express a battery of genes consistent with their observed lifestyle coherent with the capacity for phagocytosis, photosynthesis, and prototrophy (Figure 4). Presumed photo-autotrophs like members of the genus Ostreococcus lack genes consistent with the capacity for phagocytosis, but have genes consistent with the capacity for

photosynthesis and prototrophy (Figure 4). Similarly, all members of the genus Micromonas are predicted to be photo-autotrophs as they contain genes consistent with photosynthesis and prototrophy, but lack genes consistent with the capacity for phagocytosis (Figure 4). 


\section{Discussion}

We examined feeding of $M$. polaris on prey in a series of experiments with four different strains (CCMP2099, RCC2306, RCC4298 and RCC2258) grown under different light and nutrient conditions using flow cytometry to monitor prey uptake (Table 2). In none of these experiments (Figures 2, S5 and S4, Table S2), significant differences were detected between the number of M. polaris cells associated with prey at $\mathrm{T}_{0}$ and other time points $\left(\mathrm{T}_{20}\right.$ or $\left.\mathrm{T}_{40}\right)$. We also tested different fixation methods vs. live cells and three different diameters of beads $(0.5,1$, and $2 \mu \mathrm{m}$ in diameter) without detecting any suggestion of active uptake by $M$. polaris. No evidence of phago-mixotrophy was found when using the acidotropic LysoSensor dye in M. polaris lightnutrient limited cultures. Trait-based computational analysis of available genomes and transcriptomes confirmed that Micromonas lack genes consistent with the capacity for phagocytosis. These data are in contrast to what was observed for the known phagotroph $O$. triangulata (strain RCC21) that always displayed evidence of prey uptake when using similar approaches to the one we used for $M$. polaris strains and fits the computational profile of a phago-mixotroph. None of our evidence is consistent with the consideration of $M$. polaris as a phago-mixotroph.

In each of our experiments, there was a considerable number of $M$. polaris cells at $\mathrm{T}_{0}$ associated with prey, immediately following addition of prey to the cultures and before time had elapsed for prey ingestion. The percentage of cells with $0.5 \mu \mathrm{m}$ YG-beads at $\mathrm{T}_{0}$ appears to be linearly related to the bead concentration (Figure 3), suggesting the association is the result of a physical property of the cells surface rather than an active behavior that the cells execute. The external attachment of YG-beads to $M$. polaris cells was also visualized by electron microscopy (Figure S8). Such passive associations of cells with beads have recently been observed in $\mathrm{Mi}$ cromonas by Wilken et al. (2019) using flow cytometry. They observed that the proportion of cells associated with beads at $\mathrm{T}_{0}$ was much larger for heat-killed vs. live cells and that in live cells it increased with time for cultures left in the dark compared to light conditions. This contrasts with our data since we observed less attachment under dark conditions (Figure 2A). However in the Wilken et al. (2019) study cells were put in the dark for a maximum of $44 \mathrm{~h}$ (less than 2 days, their Figure $3 a$ and $b$ ) while in our case we performed the first feeding experiment after 7 days (Figure 1). Therefore in our experiment the number of cells corresponding to our 
first feeding experiment was much higher in the light than in the dark (Figure 1) and since we adjusted the bead concentration as a function of the cell concentration, the bead concentration was also much higher in the light vs. the dark condition. This explains why, based on Figure 3 (linear relationship between $\%$ of cells with beads and bead concentration), we found a much higher $\%$ of cells with beads under the light condition. External attachment of particles or bacterial cells to phytoplankton cell surfaces may be enhanced by phycosphere properties (Bell \& Mitchell 1972, Seymour et al. 2017) which mainly consist of polysaccharides released by the cells (Mühlenbruch et al. 2018, Myklestad 1995, Passow 2002a). The "stickiness" properties of abundant exopolysaccharides have mainly been studied in diatoms (Engel 2000, Passow 2002b, Seymour et al. 2017). Bacteria colonization of this sticky phycosphere occurs in both live and compromised cells and is a function of the probability of random encounters of phytoplankton and bacteria which is influenced by both bacteria concentration and motility (Seymour et al. 2017).

Our experimental conditions were very similar to those reported by McKie-Krisberg \& Sanders (2014). We used the same M. polaris strain (CCMP2099), dark and light conditions, ASW as medium, $0.5 \mu \mathrm{m}$ beads, Lugol's iodine fixation and short term incubation (40 min.). The main methodological difference is that we used flow cytometry analysis of cell suspensions instead of epifluorescence microscopy of filtered samples. Our approach has many advantages over epifluorescence microscopy: it allows counting of a much larger number of cells (typically several thousand vs. 100-200); it is faster; it results in less potential biases related to individual operator interpretation; there is no ambiguity linked to food particles randomly overlapping with cells during filtration. The latter problem is demonstrated in McKie-Krisberg \& Sanders (2014): their differential interference contrast and confocal microscopy images (Figure $1 \mathrm{c}-\mathrm{d}$ in their paper) aimed at demonstrating a YG-bead inside a $M$. polaris cell are inconclusive as the bead is at the edge of the cell (probably externally attached) which closely resembles the TEM images obtained in the present study (Figure S8). The two other papers that have reported phago-mixotrophy in Micromonas (González et al. 1993, Sanders \& Gast 2012) may have suffered from the same problem, i.e. initial attachment of prey to cells. Moreover in the Sanders \& Gast (2012) paper on natural communities the identity of the potential grazer was only "ten- 
tatively identified as Micromonas" from the presence of a DGGE band with a Micromonas sequence. A study that examined gene expression of M. polaris strain CCMP2099 under nutrient stress conditions that reportedly influence grazing rate failed to find differential expression of any gene linked to the process of phagocytosis in M. polaris (McKie-Krisberg et al. 2018). The authors propose that $M$. polaris may constitutively express phagocytosis proteins to support low-level grazing. However, a study on the model phagocyte Dictyostelium discoideum suggests that an increase in phagocytosis can indeed be linked to differential expression of genes involved in the process (Sillo et al. 2008). An alternative hypothesis regarding the gene expression results from $M$. polaris, supported by the data presented here, is that members of the genus Micromonas are not phagocytotic and therefore have no mechanism for differential expression of genes linked to phagocytosis. Sets of proteins identified as part of the phagosome compartment are broadly distributed among phagocyte and non-phagocyte organisms and only a small subset of those proteins are indicative that a species has the capacity for phagocytosis (Burns et al. 2018b). Computational models show that members of the genus Micromonas lack those indicative proteins, reinforcing our hypothesis that Micromonas is not a phago-mixotroph.

It is now acknowledged that phago-mixotrophy is a widespread trait in planktonic communities and has profound implications for marine ecosystem functioning (Flynn et al. 2019, Stoecker et al. 2017). In particular phago-mixotrophy is believed to provide a competitive advantage to photosynthetic organisms under otherwise limiting environmental conditions (e.g. low light, low nutrients). Bacterial phagocytosis has been found everywhere across the eukaryotic tree of life (Selosse et al. 2017), but most laboratory studies on phago-mixotophy have focused on a few model organisms such as the chrysophyte Ochromonas spp. (e.g. Lie et al. 2018, Terrado et al. 2017, Wilken et al. 2020), the haptophytes Prymnesium parvum (e.g. Brutemark \& Granéli 2011, Liu et al. 2015) and Chrysochromulina spp. (Hansen \& Hjorth 2002, Jones et al. 1993), and several taxa of dinoflagellate such as Alexandrium spp. (e.g. Hansen 2011, Jeong et al. 2010, Lee et al. 2016). Among green algae in addition to the works on Micromonas mentioned previously, only a few studies have been performed with 6 other species described as phago-mixotrophs: Pyramimonas gelicola (Gast et al. 2014), Pyramimonas tychotreta and Mantoniella antarctica (McKie-Krisberg et al. 2015), Cymbomonas 
tetramitiformis (Burns et al. 2015, Maruyama \& Kim 2013), Nephroselmis rotunda and $N$. pyriformis (Anderson et al. 2018). None of these species fall however in the picoplankton size range. Interestingly none of the picoplanktonic Mamiellophyceae (in addition to Micromonas) for which the trait-based computational analysis was performed (Bathycoccus, Ostreococcus, Mantoniella, including $M$. antarctica) showed evidence for phago-mixotrophy. This may suggest that the whole Mamiellophyceae class (or at least the orders Mamiellales and Bathycoccales, since we have no data for orders Dolichomastigales and Monomastigales). Despite being primary players in many environments (Tragin \& Vaulot 2018), including oligotrophic waters (Vannier et al. 2016), green picoeukaryotes are likely to rely on other strategies to thrive. Knowing the nutrition modes of this group will be important for modelling marine ecosystems since phago-mixotrophs increase the transfer of biomass to higher trophic levels resulting in larger organism mean size and sinking carbon fluxes (Ward \& Follows 2016).

The evidence presented in this paper indicating that $M$. polaris is unlikely to be phagomixotroph has profound impacts in present and future predictions of Arctic primary production, because of the importance and predicted increasing concentrations of this species in the Arctic Ocean ( $\mathrm{Li}$ et al. 2009). If indeed M. polaris is not a phago-mixotroph, the question of how it survives during the long Arctic winter (Joli et al. 2017, Vader et al. 2015) and how it is able to develop during the Spring bloom that starts with very low light condition under the snowcovered ice (Arrigo et al. 2012) remains open. 


\section{References}

Andersen, R. A., Graf, L., Malakhov, Y. \& Yoon, H. S., 2017. Rediscovery of the Ochromonas type species Ochromonas triangulata (Chrysophyceae) from its type locality (Lake Veysove, Donetsk region, Ukraine). Phycologia 56:591-604. doi:10.2216/17-15.1.

Anderson, R., Charvet, S. \& Hansen, P. J., 2018. Mixotrophy in Chlorophytes and HaptophytesEffect of Irradiance, Macronutrient, Micronutrient and Vitamin Limitation. Frontiers in Microbiology 9:1704. doi:10.3389/fmicb.2018.01704.

Arrigo, K. R., van Dijken, G. \& Pabi, S., 2008. Impact of a shrinking Arctic ice cover on marine primary production. Geophysical Research Letters 35. doi:10.1029/2008GL035028.

Arrigo, K. R., Perovich, D. K., Pickart, R. S., Brown, Z. W., Dijken, G. L. V., Lowry, K. E., Mills, M. M., Palmer, M. A., Balch, W. M., Bahr, F., Bates, N. R., Benitez-nelson, C., Bowler, B., Brownlee, E., Ehn, J. K., Frey, K. E., Garley, R., Laney, S. R., Lubelczyk, L., Mathis, J., Matsuoka, A., Mitchell, B. G., Moore, G. W. K., Ortega-retuerta, E., Pal, S., Polashenski, C. M., Reynolds, R. A., Schieber, B., Sosik, H. M., Stephens, M. \& Swift, J. H., 2012. Massive Phytoplankton Blooms Under Arctic Sea Ice. Science 336:2012.

Balzano, S., Marie, D., Gourvil, P. \& Vaulot, D., 2012. Composition of the summer photosynthetic pico and nanoplankton communities in the Beaufort Sea assessed by T-RFLP and sequences of the 18S rRNA gene from flow cytometry sorted samples. The ISME Journal 6:1480-1498. doi:10.1038/ismej.2011.213.

Bell, W. \& Mitchell, R., 1972. Chemotactic and growth responses of marine bacteria to algal extracellular products. Biological Bulletin 143:265-277.

Benner, I., Irwin, A. J. \& Finkel, Z. V., 2020. Capacity of the common Arctic picoeukaryote Micromonas to adapt to a warming ocean. Limnology and Oceanography Letters 5:221227. doi:10.1002/lol2.10133.

Berge, J., Renaud, P. E., Darnis, G., Cottier, F., Last, K., Gabrielsen, T. M., Johnsen, G., Seuthe, L., Weslawski, J. M., Leu, E., Moline, M., Nahrgang, J., Søreide, J. E., Varpe, Ø., Lønne, O. J., Daase, M. \& Falk-Petersen, S., 2015. In the dark: A review of ecosystem processes during the Arctic polar night. Progress in Oceanography 139:258-271. doi: 10.1016/j.pocean.2015.08.005. 
Box, J. E., Colgan, W. T., Christensen, T. R., Schmidt, N. M., Lund, M., Parmentier, F.-J. W., Brown, R., Bhatt, U. S., Euskirchen, E. S., Romanovsky, V. E., Walsh, J. E., Overland, J. E., Wang, M., Corell, R. W., Meier, W. N., Wouters, B., Mernild, S., Mård, J., Pawlak, J. \& Olsen, M. S., 2019. Key indicators of Arctic climate change: 1971-2017. Environmental Research Letters 14:045010. doi:10.1088/1748-9326/aafc1b.

Brown, N. J., Nilsson, J. \& Pemberton, P., 2019. Arctic ocean freshwater dynamics: Transient response to increasing river runoff and precipitation. Journal of Geophysical Research: Oceans 124:5205-5219. doi:10.1029/2018JC014923.

Brutemark, A. \& Granéli, E., 2011. Role of mixotrophy and light for growth and survival of the toxic haptophyte Prymnesium parvum. Harmful Algae 10:388-394. doi:10.1016/j.hal. 2011.01.005.

Burns, J. A., Paasch, A., Narechania, A. \& Kim, E., 2015. Comparative Genomics of a Bacterivorous Green Alga Reveals Evolutionary Causalities and Consequences of PhagoMixotrophic Mode of Nutrition. Genome Biology and Evolution 7:3047-3061. doi: 10.1093/gbe/evv144.

Burns, J. A., Pittis, A. A. \& Kim, E., 2018a. Gene-based predictive models of trophic modes suggest Asgard archaea are not phagocytotic. Nature Ecology and Evolution 2:697-704. doi:10.1038/s41559-018-0477-7.

Burns, J. A., Pittis, A. A. \& Kim, E., 2018b. Gene-based predictive models of trophic modes suggest Asgard archaea are not phagocytotic. Nature Ecology \& Evolution 2:697-704. doi:10.1038/s41559-018-0477-7.

Caron, D. A., 2016. Mixotrophy stirs up our understanding of marine food webs. Proceedings of the National Academy of Sciences of the United States of America 113:2806-2808. doi:10.1073/pnas.1600718113.

Carvalho, W. F. \& Graneli, E., 2006. Acidotropic probes and flow cytometry : a powerful combination for detecting phagotrophy in mixotrophic and heterotrophic protists. Aquatic microbial ecology 44:85-96.

Coupel, P., Ruiz-Pino, D., Sicre, M. A., Chen, J. F., Lee, S. H., Schiffrine, N., Li, H. L. \& Gascard, J. C., 2015. The impact of freshening on phytoplankton production in the Pacific Arc- 
tic Ocean. Progress in Oceanography 131:113-125. doi:10.1016/j.pocean.2014.12.003.

Engel, A., 2000. The role of transparent exopolymer particles (TEP) in the increase in apparent particle stickiness $(\alpha)$ during the decline of a diatom bloom. Journal of Plankton Research 22:485-497. doi:10.1093/plankt/22.3.485.

Flynn, K. J., Mitra, A., Anestis, K., Anschütz, A. A., Calbet, A., Ferreira, G. D., Gypens, N., Hansen, P. J., John, U., Martin, J. L., Mansour, J. S., Maselli, M., Medić, N., Norlin, A., Not, F., Pitta, P., Romano, F., Saiz, E., Schneider, L. K., Stolte, W. \& Traboni, C., 2019. Mixotrophic protists and a new paradigm for marine ecology: Where does plankton research go now? Journal of Plankton Research 41:375-391. doi:10.1093/plankt/fbz026.

Gast, R. J., McKie-Krisberg, Z. M., Fay, S. A., Rose, J. M. \& Sanders, R. W., 2014. Antarctic mixotrophic protist abundances by microscopy and molecular methods. FEMS Microbiology Ecology 89:388-401. doi:10.1111/1574-6941.12334.

González, J. M., Sherr, B. \& Sherr, E. B., 1993. Digestive enzyme activity as a quantitative measure of protistan grazing: the acid lysozyme assay for bacterivory. Marine Ecology Progress Series 100:197-206. doi:10.3354/meps 100197.

Graversen, R. G., Mauritsen, T., Tjernström, M., Källén, E. \& Svensson, G., 2008. Vertical structure of recent Arctic warming. Nature 451:53.

Guillard, R. R. L. \& Hargraves, P. E., 1993. Stichochrysis immobilis is a diatom, not a chrysophyte. Phycologia 32:234-236. doi:doi:10.2216/i0031-8884-32-3-234.1.

Hansen, P. E. R. J., 2011. The Role of Photosynthesis and Food Uptake for the Growth of Marine Mixotrophic Dinoflagellates. Journal of Eukaryotic Microbiology 58:203-214. doi: 10.1111/j.1550-7408.2011.00537.x.

Hansen, P. J. \& Hjorth, M., 2002. Growth and grazing responses of Chrysochromulina ericina. Marine Biology 141:975-983. doi:10.1007/s00227-002-0879-5.

Hartmann, M., Grob, C., Tarran, G. A., Martin, A. P., Burkill, P. H., Scanlan, D. J. \& Zubkov, M. V., 2012. Mixotrophic basis of Atlantic oligotrophic ecosystems. Proceedings of the National Academy of Sciences of the United States of America 109:5756-5760. doi:10. 1073/pnas.1118179109.

Hoppe, C. J. M., Flintrop, C. M. \& Rost, B., 2018. The Arctic picoeukaryote Micromonas 
pusilla benefits synergistically from warming and ocean acidification. Biogeosciences 15:4353-4365. doi:10.5194/bg-15-4353-2018.

Jeong, H. J., Yoo, Y. D., Kim, J. S., Seong, K. A., Kang, N. S. \& Kim, T. H., 2010. Growth, feeding and ecological roles of the mixotrophic and heterotrophic dinoflagellates in marine planktonic food webs. Ocean Science Journal 45:65-91. doi:10.1007/ s12601-010-0007-2.

Joli, N., Monier, A., Logares, R. \& Lovejoy, C., 2017. Seasonal patterns in Arctic prasinophytes and inferred ecology of Bathycoccus unveiled in an Arctic winter metagenome. The ISME Journal 11:1372-1385. doi:10.1038/ismej.2017.7.

Jones, H. L. J., Leadbeater, B. S. C. \& Green, J. C., 1993. Mixotrophy in marine species of Chrysochromulina (Prymnesiophyceae): ingestion and digestion of a small green flagellate. Journal of the Marine Biological Association of the United Kingdom 73:283-296. doi:DOI:10.1017/S0025315400032859.

Kahru, M., Lee, Z., Mitchell, B. G. \& Nevison, C. D., 2016. Effects of sea ice cover on satellitedetected primary production in the Arctic Ocean. Biology letters 12:20160223. doi:10. 1098/rsbl.2016.0223.

Keeling, P. J., Burki, F., Wilcox, H. M., Allam, B., Allen, E. E., Amaral-Zettler, L. A., Armbrust, E. V., Archibald, J. M., Bharti, A. K., Bell, C. J., Beszteri, B., Bidle, K. D., Cameron, C. T., Campbell, L., Caron, D. A., Cattolico, R. A., Collier, J. L., Coyne, K., Davy, S. K., Deschamps, P., Dyhrman, S. T., Edvardsen, B., Gates, R. D., Gobler, C. J., Greenwood, S. J., Guida, S. M., Jacobi, J. L., Jakobsen, K. S., James, E. R., Jenkins, B., John, U., Johnson, M. D., Juhl, A. R., Kamp, A., Katz, L. A., Kiene, R., Kudryavtsev, A., Leander, B. S., Lin, S., Lovejoy, C., Lynn, D., Marchetti, A., McManus, G., Nedelcu, A. M., Menden-Deuer, S., Miceli, C., Mock, T., Montresor, M., Moran, M. A., Murray, S., Nadathur, G., Nagai, S., Ngam, P. B., Palenik, B., Pawlowski, J., Petroni, G., Piganeau, G., Posewitz, M. C., Rengefors, K., Romano, G., Rumpho, M. E., Rynearson, T., Schilling, K. B., Schroeder, D. C., Simpson, A. G. B., Slamovits, C. H., Smith, D. R., Smith, G. J., Smith, S. R., Sosik, H. M., Stief, P., Theriot, E., Twary, S. N., Umale, P. E., Vaulot, D., Wawrik, B., Wheeler, G. L., Wilson, W. H., Xu, Y., Zingone, A. \& Worden, A. Z., 2014. 
The Marine Microbial Eukaryote Transcriptome Sequencing Project (MMETSP): Illuminating the Functional Diversity of Eukaryotic Life in the Oceans through Transcriptome Sequencing. PLoS Biol 12:e1001889. doi:10.1371/journal.pbio.1001889.

Keller, M. D., Selvin, R. C., Claus, W. \& Guillard, R. R. L., 1987. Media for the culture of oceanic ultraphytoplankton. Journal of Phycology 23:633-638. doi:10.1111/j.1529-8817. 1987.tb04217.x.

Kilias, E., Kattner, G., Wolf, C., Frickenhaus, S. \& Metfies, K., 2014. A molecular survey of protist diversity through the central Arctic Ocean. Polar Biology 37:1271-1287. doi: 10.1007/s00300-014-1519-5.

Lee, K. H., Jeong, H. J., Kwon, J. E., Kang, H. C., Kim, J. H., Jang, S. H., Park, J. Y., Yoon, E. Y. \& Kim, J. S., 2016. Mixotrophic ability of the phototrophic dinoflagellates Alexandrium andersonii, A. affine, and A. fraterculus. Harmful Algae 59:67-81. doi:10.1016/j.hal.2016. 09.008 .

Leles, S. G., Mitra, A., Flynn, K. J., Tillmann, U., Stoecker, D., Jeong, H. J., Burkholder, J., Hansen, P. J., Caron, D. A., Glibert, P. M., Hallegraeff, G., Raven, J. A., Sanders, R. W. \& Zubkov, M., 2019. Sampling bias misrepresents the biogeographical significance of constitutive mixotrophs across global oceans. Global Ecology and Biogeography 28:418428. doi:10.1111/geb.12853.

Li, W. K., McLaughlin, F. A., Lovejoy, C. \& Carmack, E. C., 2009. Smallest algae thrive as the Arctic Ocean freshens. Science 326:539. doi:10.1126/science.1179798.

Lie, A. A. Y., Liu, Z., Terrado, R., Tatters, A. O., Heidelberg, K. B. \& Caron, D. A., 2018. A tale of two mixotrophic chrysophytes: Insights into the metabolisms of two Ochromonas species (Chrysophyceae) through a comparison of gene expression. PLOS ONE 13:e0192439.

Liu, Z., Koid, A. E., Terrado, R., Campbell, V., Caron, D. A. \& Heidelberg, K. B., 2015. Changes in gene expression of Prymnesium parvum induced by nitrogen and phosphorus limitation. Front Microbiol 6:631. doi:10.3389/fmicb.2015.00631.

Lovejoy, C., Vincent, W. F., Bonilla, S., Roy, S., Martineau, M. J., Terrado, R., Potvin, M., Massana, R. \& Pedros-Alio, C., 2007. Distribution, phylogeny, and growth of cold-adapted 
picoprasinophytes in arctic seas. Journal of Phycology 43:78-89.

Maia, R., Eliason, C. M., Bitton, P.-P., Doucet, S. M. \& Shawkey, M. D., 2013. pavo: an r package for the analysis, visualization and organization of spectral data. Methods in Ecology and Evolution 4:906-913.

Marquardt, M., Vader, A., Stübner, E. I., Reigstad, M. \& Gabrielsen, T. M., 2016. Strong Seasonality of Marine Microbial Eukaryotes in a High-Arctic Fjord (Isfjorden, in West Spitsbergen, Norway). Applied and Environmental microbiology 82:1868-1880. doi: 10.1128/AEM.03208-15.

Maruyama, S. \& Kim, E., 2013. A modern descendant of early green algal phagotrophs. Curr Biol 23:1081-1084. doi:10.1016/j.cub.2013.04.063.

McKie-Krisberg, Z. M. \& Sanders, R. W., 2014. Phagotrophy by the picoeukaryotic green alga Micromonas: implications for Arctic Oceans. The ISME Journal 10:1953-1961.

McKie-Krisberg, Z. M., Gast, R. J. \& Sanders, R. W., 2015. Physiological Responses of Three Species of Antarctic Mixotrophic Phytoflagellates to Changes in Light and Dissolved Nutrients. Microbial Ecology 70:21-29. doi:10.1007/s00248-014-0543-X.

McKie-Krisberg, Z. M., Sanders, R. W. \& Gast, R. J., 2018. Evaluation of MixotrophyAssociated Gene Expression in Two Species of Polar Marine Algae. Frontiers in Marine Science 5:1-12. doi:10.3389/fmars.2018.00273.

Millette, N. C., Pierson, J. J., Aceves, A. \& Stoecker, D. K., 2017. Mixotrophy in Heterocapsa rotundata: A mechanism for dominating the winter phytoplankton. Limnology and Oceanography 62:836-845. doi:10.1002/1no.10470.

Mitra, A., Flynn, K. J., Burkholder, J. M., Berge, T., Calbet, A., Raven, J. A., Granéli, E., Glibert, P. M., Hansen, P. J., Stoecker, D. K., Thingstad, F., Tillmann, U., Våge, S., Wilken, S. \& Zubkov, M. V., 2014. The role of mixotrophic protists in the biological carbon pump. Biogeosciences 11:995-1005. doi:10.5194/bg-11-995-2014.

Mühlenbruch, M., Grossart, H.-P., Eigemann, F. \& Voss, M., 2018. Mini-review: Phytoplankton-derived polysaccharides in the marine environment and their interactions with heterotrophic bacteria. Environmental Microbiology 20:2671-2685. doi:10.1111/ 1462-2920.14302. 
Myklestad, S. M., 1995. Release of extracellular products by phytoplankton with special emphasis on polysaccharides. Science of The Total Environment 165:155-164. doi:10.1016/ 0048-9697(95)04549-G.

Nummelin, A., Ilicak, M., Li, C. \& Smedsrud, L. H., 2016. Consequences of future increased Arctic runoff on Arctic Ocean stratification, circulation, and sea ice cover. Journal of Geophysical Research: Oceans 121:617-637. doi:10.1002/2015JC011156.

Park, J.-Y., Kug, J.-S., Bader, J., Rolph, R. \& Kwon, M., 2015. Amplified Arctic warming by phytoplankton under greenhouse warming. Proceedings of the National Academy of Sciences of the United States of America 112:5921-5926. doi:10.1073/pnas.1416884112.

Passow, U., 2002a. Production of transparent exopolymer particles (TEP) by phyto- and bacterioplankton. Marine Ecology-progress Series 236:1-12. doi:10.3354/meps236001.

Passow, U., 2002b. Transparent exopolymer particles (TEP) in aquatic environments. Progress in Oceanography 55:287-333. doi:10.1016/S0079-6611(02)00138-6.

Paulsen, M. L., Doré, H., Garczarek, L., Seuthe, L., Müller, O., Sandaa, R.-A., Bratbak, G. \& Larsen, A., 2016. Synechococcus in the Atlantic Gateway to the Arctic Ocean. Frontiers in Marine Science 3. doi:10.3389/fmars.2016.00191.

R Core Team, 2014. R: A Language and Environment for Statistical Computing. R Foundation for Statistical Computing, Vienna, Austria.

Renaut, S., Devred, E. \& Babin, M., 2018. Northward Expansion and Intensification of Phytoplankton Growth During the Early Ice-Free Season in Arctic. Geophysical Research Letters 45:10,510-590,598. doi:10.1029/2018GL078995.

Sanders, R. \& Gast, R., 2012. Bacterivory by phototrophic picoplankton and nanoplankton in Arctic waters. FEMS microbiology ecology 82:242-253. doi:10.1111/j.1574-6941.2011. 01253.x.

Selosse, M.-A., Charpin, M. \& Not, F., 2017. Mixotrophy everywhere on land and in water: the grand écart hypothesis. Ecology Letters 20:246-263. doi:10.1111/ele.12714.

Seymour, J. R., Amin, S. A., Raina, J.-B. \& Stocker, R., 2017. Zooming in on the phycosphere: the ecological interface for phytoplankton-bacteria relationships. Nature Microbiology 2:17065. doi:10.1038/nmicrobiol.2017.65. 
Sherr, E. \& Sherr, B., 1993. Protistan grazing rates via uptake of fluorescently labeled prey. In Kemp, P., Sherr, B., Sherr, E. \& Cole, J., editors, Handbook of Methods in Aquatic Microbial Ecology, pp. 695-701. Lewis Publishers: Boca Raton, USA.

Sherr, B. F., Sherr, E. B. \& Fallon, R. D., 1987. Use of Monodispersed, Fluorescently Labeled Bacteria to Estimate In Situ Protozoan Bacterivory. Applied and Environmental Microbiology 53:958-965. doi:10.1128/AEM.53.5.958-965.1987.

Sillo, A., Bloomfield, G., Balest, A., Balbo, A., Pergolizzi, B., Peracino, B., Skelton, J., Ivens, A. \& Bozzaro, S., 2008. Genome-wide transcriptional changes induced by phagocytosis or growth on bacteria in Dictyostelium. BMC genomics 9:291.

Simon, N., Foulon, E., Grulois, D., Six, C., Desdevises, Y., Latimier, M., Le Gall, F., Tragin, M., Houdan, A., Derelle, E., Jouenne, F., Marie, D., Le Panse, S., Vaulot, D. \& Marin, B., 2017. Revision of the Genus Micromonas Manton et Parke (Chlorophyta, Mamiellophyceae), of the Type Species M. pusilla (Butcher) Manton \& Parke and of the Species M. commoda van Baren, Bachy and Worden and Description of Two New Species Based on the Genetic and Phenotypic Characterization of Cultured Isolates. Protist 168:612-635. doi:10.1016/ j.protis.2017.09.002.

Slagstad, D., Wassmann, P. F. J. \& Ellingsen, I., 2015. Physical constrains and productivity in the future Arctic Ocean. Frontiers in Marine Science 2:1-23. doi:10.3389/fmars.2015. 00085.

Stoecker, D. K. \& Lavrentyev, P. J., 2018. Mixotrophic Plankton in the Polar Seas: A Pan-Arctic Review. Frontiers in Marine Science 5. doi:10.3389/fmars.2018.00292.

Stoecker, D. K., Hansen, P. J., Caron, D. A. \& Mitra, A., 2017. Mixotrophy in the Marine Plankton. Annual Review of Marine Science 9:311-335. doi:10.1146/ annurev-marine-010816-060617.

Tedesco, L., Vichi, M. \& Scoccimarro, E., 2019. Sea-ice algal phenology in a warmer Arctic. Science Advances 5:eaav4830. doi:10.1126/sciadv.aav4830.

Terrado, R., Pasulka, A. L., Lie, A. A.-Y., Orphan, V. J., Heidelberg, K. B. \& Caron, D. A., 2017. Autotrophic and heterotrophic acquisition of carbon and nitrogen by a mixotrophic chrysophyte established through stable isotope analysis. The ISME Journal 11:2022. 
Timmermans, M.-L., Proshutinsky, A., Krishfield, R. A., Perovich, D. K., Richter-Menge, J. A., Stanton, T. P. \& Toole, J. M., 2011. Surface freshening in the Arctic Ocean's Eurasian Basin: An apparent consequence of recent change in the wind-driven circulation. Journal of Geophysical Research 116:C00D03. doi:10.1029/2011JC006975.

Tragin, M. \& Vaulot, D., 2018. Green microalgae in marine coastal waters: The Ocean Sampling Day (OSD) dataset. Scientific Reports 8:14020. doi:10.1038/s41598-018-32338-w.

Tremblay, J.-É., Anderson, L. G., Matrai, P., Coupel, P., Bélanger, S., Michel, C. \& Reigstad, M., 2015. Global and regional drivers of nutrient supply, primary production and CO2 drawdown in the changing Arctic Ocean. Progress in Oceanography 139:171-196. doi: 10.1016/j.pocean.2015.08.009.

Unrein, F., Gasol, J. M., Not, F., Forn, I. \& Massana, R., 2014. Mixotrophic haptophytes are key bacterial grazers in oligotrophic coastal waters. The ISME Journal 8:164-176. doi: 10.1038/ismej.2013.132.

Vader, A., Marquardt, M., Meshram, A. R. \& Gabrielsen, T. M., 2015. Key Arctic phototrophs are widespread in the polar night. Polar Biology 38:13-21. doi:10.1007/ s00300-014-1570-2.

van Baren, M. J., Bachy, C., Reistetter, E. N., Purvine, S. O., Grimwood, J., Sudek, S., Yu, H., Poirier, C., Deerinck, T. J., Kuo, A., Grigoriev, I. V., Wong, C.-H., Smith, R. D., Callister, S. J., Wei, C.-L., Schmutz, J. \& Worden, A. Z., 2016. Evidence-based green algal genomics reveals marine diversity and ancestral characteristics of land plants. BMC Genomics 17:122. doi:10.1186/s12864-016-2585-6.

Vannier, T., Leconte, J., Seeleuthner, Y., Mondy, S., Pelletier, E., Aury, J.-M., de Vargas, C., Sieracki, M., Iudicone, D., Vaulot, D., Wincker, P. \& Jaillon, O., 2016. Survey of the green picoalga Bathycoccus genomes in the global ocean. Scientific Reports 6:37900. doi: 10.1038/srep37900.

Ward, B. A., 2015. Temperature-Correlated Changes in Phytoplankton Community Structure Are Restricted to Polar Waters. PLOS ONE 10:e0135581.

Ward, B. A. \& Follows, M. J., 2016. Marine mixotrophy increases trophic transfer efficiency, mean organism size, and vertical carbon flux. Proceedings of the National Academy of Sci- 
ences of the United States of America 113:2958 LP - 2963. doi:10.1073/pnas.1517118113.

Wassmann, P., 2015. Overarching perspectives of contemporary and future ecosystems in the Arctic Ocean. Progress in Oceanography 139:1-12. doi:10.1016/j.pocean.2015.08.004.

Wilken, S., Yung, C. C. M., Hamilton, M., Hoadley, K., Nzongo, J., Eckmann, C., CorrochanoLuque, M., Poirier, C. \& Worden, A. Z., 2019. The need to account for cell biology in characterizing predatory mixotrophs in aquatic environments. Philosophical Transactions of the Royal Society B: Biological Sciences 374:20190090. doi:10.1098/rstb.2019.0090.

Wilken, S., Choi, C. J. \& Worden, A. Z., 2020. Contrasting Mixotrophic Lifestyles Reveal Different Ecological Niches in Two Closely Related Marine Protists. Journal of Phycology 56:52-67. doi:10.1111/jpy.12920.

Worden, A. Z., Lee, J. H., Mock, T., Rouze, P., Simmons, M. P., Aerts, A. L., Allen, A. E., Cuvelier, M. L., Derelle, E., Everett, M. V., Foulon, E., Grimwood, J., Gundlach, H., Henrissat, B., Napoli, C., McDonald, S. M., Parker, M. S., Rombauts, S., Salamov, A., Von Dassow, P., Badger, J. H., Coutinho, P. M., Demir, E., Dubchak, I., Gentemann, C., Eikrem, W., Gready, J. E., John, U., Lanier, W., Lindquist, E. A., Lucas, S., Mayer, K. F., Moreau, H., Not, F., Otillar, R., Panaud, O., Pangilinan, J., Paulsen, I., Piegu, B., Poliakov, A., Robbens, S., Schmutz, J., Toulza, E., Wyss, T., Zelensky, A., Zhou, K., Armbrust, E. V., Bhattacharya, D., Goodenough, U. W., Van de Peer, Y. \& Grigoriev, I. V., 2009. Green evolution and dynamic adaptations revealed by genomes of the marine picoeukaryotes Micromonas. Science 324:268-272. doi:324/5924/268[pii]10.1126/science.1167222.

Zhang, Q., Gradinger, R. \& Spindler, M., 1998. Dark Survival of Marine Microalgae in the High Arctic (Greenland Sea). Polarforschung 65:111-116. 


\section{Acknowledgments}

This work was supported by ANR contract PhytoPol (ANR-15-CE02-0007). We thank Robert Sanders and Rebecca Gast for hosting VJ and training her on techniques to determine mixotrophy in phytoplankton. We also thank Dominique Marie for help with flow cytometry, Christian Jeanthon for help and advice with fluorescently labelled bacteria, Sophie Le Panse from the Merimage microscopy platform at the Roscoff Marine Station for assistance with the transmission electron micrographs and the Roscoff Culture Collection for providing of the algal strains.

\section{Author contributions statement}

DV and VJ conceived the study. VJ and FLG collected and processed the samples. VJ, JB and DV analyzed the data. VJ, JB and DV drafted the manuscript. VJ, DV, FLG, FN and JB edited the final version of the paper.

\section{Additional information}

\section{Data availability}

Protocols are available at protocols.io at https://www.protocols.io/edit/mixotrophyquantification-of-the-percent-of-phytop-be2vjge6/steps. Scripts for trophic mode prediction and visualization are available at https://github.com/burnsajohn/predictTrophicMode.

\section{Competing interests}

The authors declare no competing interests. 


\section{List of Tables}

Table 1 List of algal strains used in this study with isolation region, coordinates, depth $(\mathrm{m})$ and growth temperature $\left({ }^{\circ} \mathrm{C}\right)$.

Table 2 Experimental scheme. Replete correspond to cultures grown in Artifical Sea Water (ASW) with L1 medium components added and limited to cultures grown in ASW without any addition. Ab correspond to cultures for which $1 \mu \mathrm{l}$ of Penicillin-Streptomycin-Neomycin (PSN) antibiotics solution was added to $1 \mathrm{ml}$ of culture. The time points on which the percent of cells with prey was measured is indicated $\left(\mathrm{T}_{0}, \mathrm{~T}_{20}\right.$ and $\mathrm{T}_{40}$, where the subscript corresponds to minutes). LR: Light nutrient replete, LL: Light nutrient limited, DR: Dark nutrient replete, DL: Dark nutrient limited, LR-Ab: Light nutrient replete with antibiotics.

Table S1 List of strains used for transcriptome analysis. MMETSP corresponds to the Marine Microbial Eukaryote Transcriptome Sequencing Project (Keeling et al. 2014). METDB corresponds to the micro-eukaryotic marine species transcriptomes database available from http://metdb.sbroscoff.fr/metdb/.

Table S2 Summary of experimental conditions and results for all experiment performed with $M$. Polaris and $O$. triangulata strains. The percent of cells with prey (mean \pm sd) is indicated for each time point after the addition of prey ( $\mathrm{T}_{0}, \mathrm{~T}_{20}$ and $\mathrm{T}_{40}$, where the subscript corresponds to minutes). The last four columns correspond to Student and Welsh p-values.

Table S3 Comparison of feeding on three different YG-bead sizes (diamter 0.5, 1, and $2 \mu \mathrm{m}$ ) for $M$. polaris (EXP7). The percent of cells with prey (mean \pm sd) was measured independently for each bead size and is indicated for each time point $\left(\mathrm{T}_{0}\right.$ and $\mathrm{T}_{40}$, where the subscript correspond to minutes).

Table S4 Comparison of Lugol's iodine and glutaraldehyde fixation, and live (no fixation) measurements of the percent of $M$. polaris cells with YG-beads (EXP6). The percent of cells with prey (mean \pm sd) is indicated for each time point after the addition of prey $\left(\mathrm{T}_{0}\right.$ and $\mathrm{T}_{40}$, where the subscript corresponds to minutes).

Table S5 Lysosensor experiment (EXP9). Last column shows the mean \pm sd Lysosensor green. 


\section{List of Figures}

Figure 1 Growth curves for each $M$. polaris strain grown under four treatments (M. polaris-EXP1). Arrows indicate the time point (days) when a feeding experiment was performed. Error bars correspond to standard deviation and in some cases are smaller than the symbol used.

Figure 2 A. Percent of M. polaris strains CCMP2009 and RCC4298 cells with YG-beads (M. polaris-EXP1) for different treatments. Two feeding experiments were performed. B. Percent of M. polaris strain RCC4298 and O. triangulata strain RCC21 cells with FLBs and YG-beads (EXP3). The color of the bars corresponds to the time after the addition of YGbeads ( 0 minutes; light grey, 20 minutes; dark grey, 40 minutes; black). Error bars correspond to standard deviation.

Figure 3 Relationship between percent of cells with YG-beads and bead concentration immediately after the addition of YG-beads $\left(\mathrm{T}_{0}\right)$. The line and spread represents a fitted linear relationship $\left(\mathrm{R}^{2}=0.93\right)$. Circles correspond to $M$. polaris and triangles to $O$. triangulata experiments.

Figure 4 Trophic mode predictions from genome and transcriptome analysis. Predictions in three dimensions, phagocytosis, photosynthesis, and prototrophy were projected onto the circle. Shaded regions indicate regions where 0 (parasite, gray, lower edges) to all 3 (phago-mixotroph, blue, upper central region) predictions cross the positive threshold of 50\% probability of a strain possessing a given function. Organisms positive for phagotrophy are in the upper hemisphere. Organisms positive for photosynthesis are in the middle to right region. Organisms positive for prototrophy are in the middle to left region. Organisms negative for all predictions are in the lower gray edge regions. Strains in bold correspond to those used in the feeding experiments. 
Figure S1 Examples of flow cytograms for M. polaris and the positive control $O$. triangulata. Flow cytometry was used to determine the percent of cells with prey (YG-beads and FLBs) in fixed samples using a protocol modified from Sherr \& Sherr (1993). Data collection was performed with threshold on red $(695 \pm 50 \mathrm{~nm}$ band pass filter) or green fluorescence (525 $\pm 30 \mathrm{~nm}$ band pass filter). Cells that displayed red autofluorescence from chlorophyll as well as green fluorescence were considered to be containing prey (cells with YG-beads in green, cells with FLBs in orange and cells without prey in blue). In addition, to confirm the total concentration of prey added to each experimental flask, the same sample was also run with the threshold on green fluorescence (YG-beads and FLBs in grey and black respectively).

Figure S2 Flow cytograms of $O$. triangulata and $M$. polaris before (purple) and after (green) staining with Lysosensor. Red fluorescence corresponds to chlorophyll fluorescence, while green fluorescence corresponds to autofluorescence before staining or to Lysosensor fluorescence after staining. Green fluorescence clearly increases after Lysosensor staining for O. triangulata and not for M. polaris.

Figure S3 Change in forward scatter and red chlorophyll fluorescence measured by flow cytometry during the experiments reported in Figure 1 (M. polarisEXP1).

Figure S4 Percent of $M$. polaris cells with YG-beads (M. polaris-EXP1) for strains RCC2258 and RCC2306 and different treatments. Two feeding experiments were performed. The color of the bars represent the time point (in minutes) after the addition of YG-beads (0 minutes; light grey, 20 minutes; dark grey, 40 minutes; black). Error bars correspond to standard deviation.

Figure S5 Percent of M. polaris cells with YG-beads (M. polaris-EXP2) for each strain and treatment. The color of the bars represents the time point (in minutes) after the addition of YG-beads ( 0 minutes; light grey, 20 minutes; dark grey, 40 minutes; black). Replete Ab correspond to nutrient replete conditions with antibiotics. 
Figure S6 Changes with time in the number of M. polaris (strain RCC2306) cells with YG-beads measured by continuously running a live sample for 20 minutes immediately after the addition of YG-beads. Two ratios of beads to cells were tested, $1: 1$ and $2: 1$, each in duplicate.

Figure S7 Flow cytograms for M. polaris cells incubated with YG-beads of three different sizes: 0.5 (green), 1.0 (orange) and 2.0 (red) $\mu \mathrm{m}$. See legend of Figure S1 for details.

Figure S8 Transmission electron microscopy images of $M$. polaris (strain RCC2306) with YG-beads $(0.5 \mu \mathrm{m})$ after negative staining. A. Arrow indicates a $M$. polaris cell with a YG-bead. B and C. Close up views of M. polaris cells with attached YG-bead. 
Table 1. List of algal strains used in this study with isolation region, coordinates, depth (m) and growth temperature $\left({ }^{\circ} \mathrm{C}\right)$.

\begin{tabular}{|c|c|c|c|c|c|}
\hline Species & Strain & Origin & Lat Long & Depth & Temperature \\
\hline \multirow{4}{*}{ M. polaris } & CCMP2099 & Arctic, Baffin Bay & $76^{\circ} \mathrm{N} 75^{\circ} \mathrm{W}$ & 55 & 4 \\
\hline & RCC2306 & Arctic, Beaufort Sea & $71^{\circ} \mathrm{N} 132^{\circ} \mathrm{W}$ & 70 & 4 \\
\hline & RCC4298 & Arctic, Greenland Sea & $82^{\circ} \mathrm{N} 20^{\circ} \mathrm{E}$ & 20 & 4 \\
\hline & RCC2288 & Arctic, Beaufort Sea & $70^{\circ} \mathrm{N} 135^{\circ} \mathrm{W}$ & 0 & 4 \\
\hline O. triangulata & RCC21 & Atlantic, Bay of Biscay & $48^{\circ} \mathrm{N} 4^{\circ} \mathrm{W}$ & - & 20 \\
\hline
\end{tabular}

Table 2. Experimental scheme. Replete correspond to cultures grown in Artifical Sea Water (ASW) with L1 medium components added and limited to cultures grown in ASW without any addition. Ab correspond to cultures for which $1 \mu$ l of Penicillin-Streptomycin-Neomycin (PSN) antibiotics solution was added to $1 \mathrm{ml}$ of culture. The time points on which the percent of cells with prey was measured is indicated ( $\mathbf{T}_{0}, \mathbf{T}_{20}$ and $\mathbf{T}_{40}$, where the subscript corresponds to minutes). LR: Light nutrient replete, LL: Light nutrient limited, DR: Dark nutrient replete, DL: Dark nutrient limited, LR-Ab: Light nutrient replete with antibiotics.

\begin{tabular}{llllll}
\hline Code & Conditions & Prey & Genus & Time points (mins) & Goal \\
\hline EXP1 & LR, LL, DR, DL & YG-beads & Micromonas, Ochromonas & $0,20,40$ & Basic experiment with beads \\
EXP2 & LR, LL, DR, DL, LR-Ab & YG-beads & Micromonas, Ochromonas & $0,20,40$ & Test effect of antibiotics \\
EXP3 & LR & YG-beads, FLBs & Micromonas, Ochromonas & 0,40 & Compare beads vs FLBs \\
EXP4 & LR & FLBs & Ochromonas & 0,40 & Test FLBs on Ochromonas \\
EXP5 & LR, LL, DR, DL, LR-Ab & YG-beads & Micromonas & 0 & Test attachment of preys at T0 \\
EXP6 & LR & YG-beads & Micromonas & 0,40 & Test effect of fixation \\
EXP7 & LL & YG-beads & Micromonas & 0,40 & Test effect of bead size \\
EXP8 & LR & YG-beads & Micromonas & 0 to 20 & Time course of bead attachment \\
EXP9 & LL & YG-beads & Micromonas, Ochromonas & Test Lysosensor (food vacuoles) \\
\hline
\end{tabular}




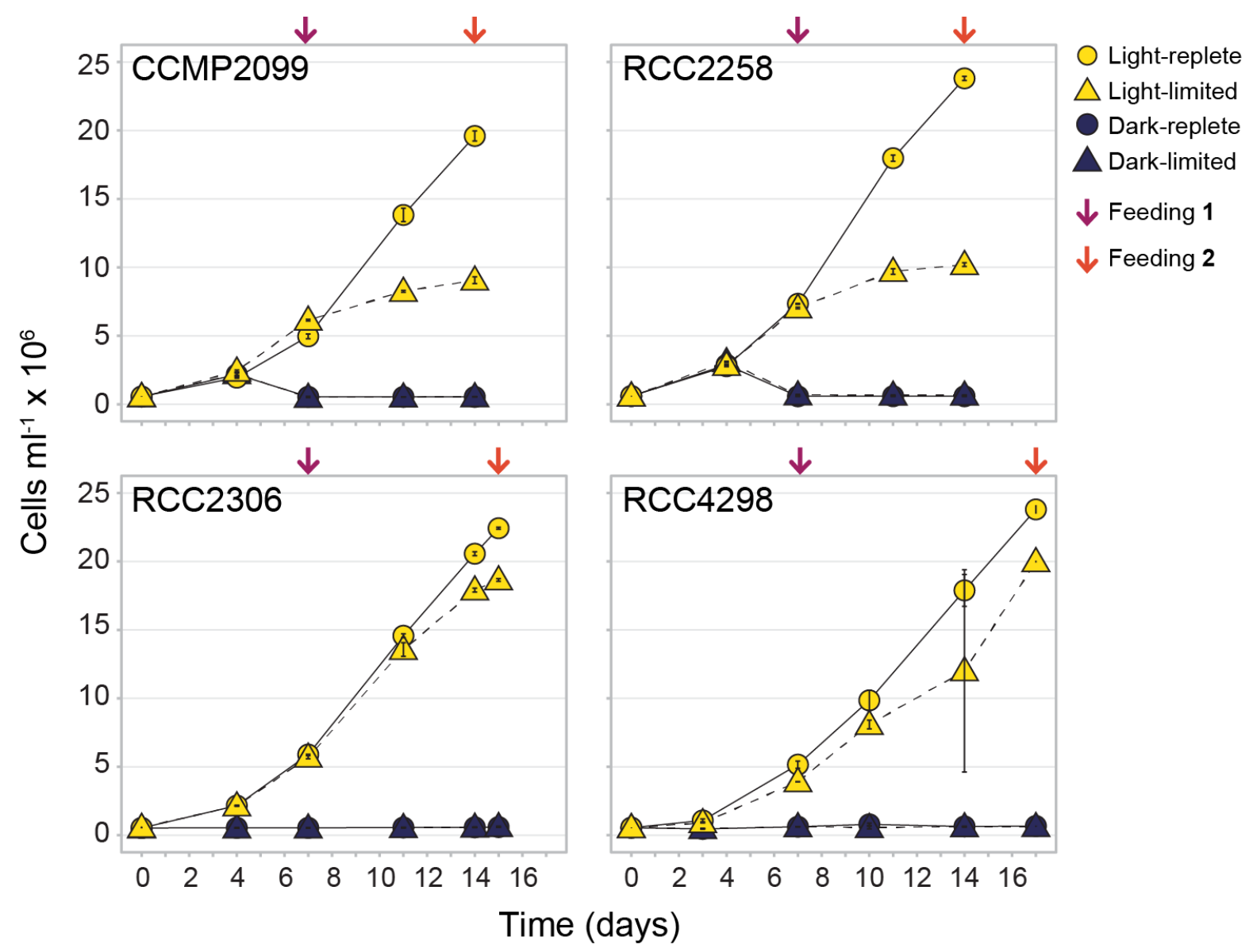

Figure 1. Growth curves for each $M$. polaris strain grown under four treatments $(M$. polaris-EXP1). Arrows indicate the time point (days) when a feeding experiment was performed. Error bars correspond to standard deviation and in some cases are smaller than the symbol used. 
A

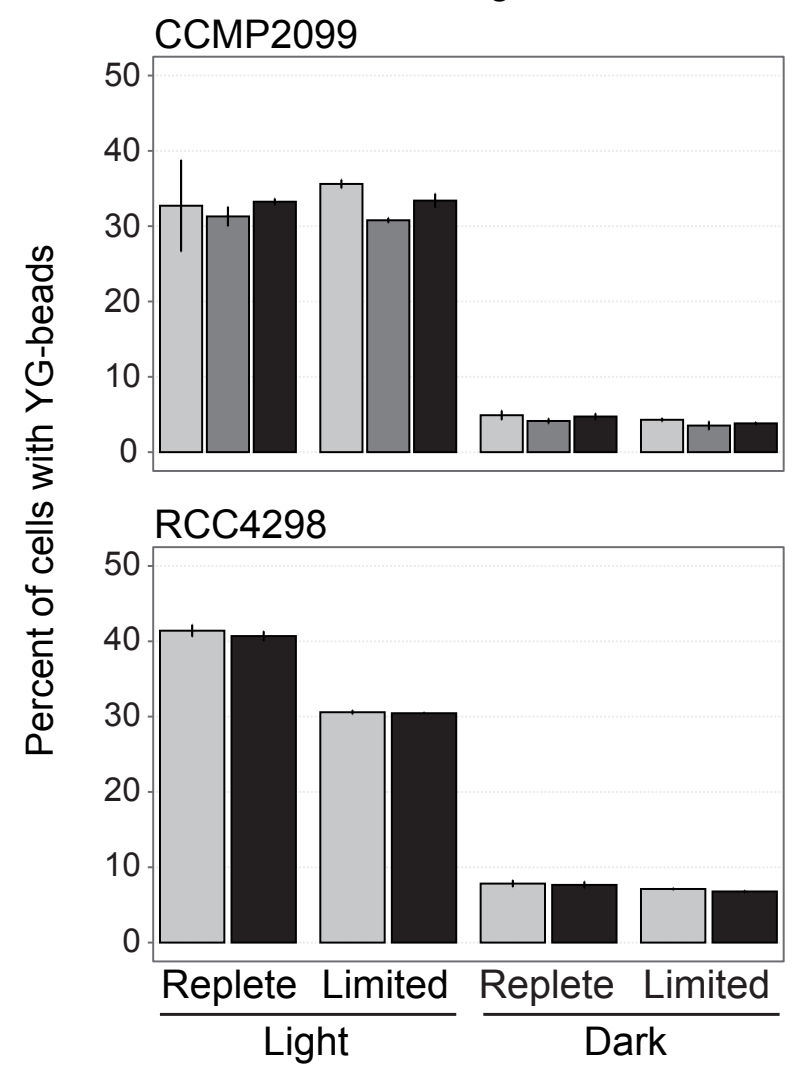

B

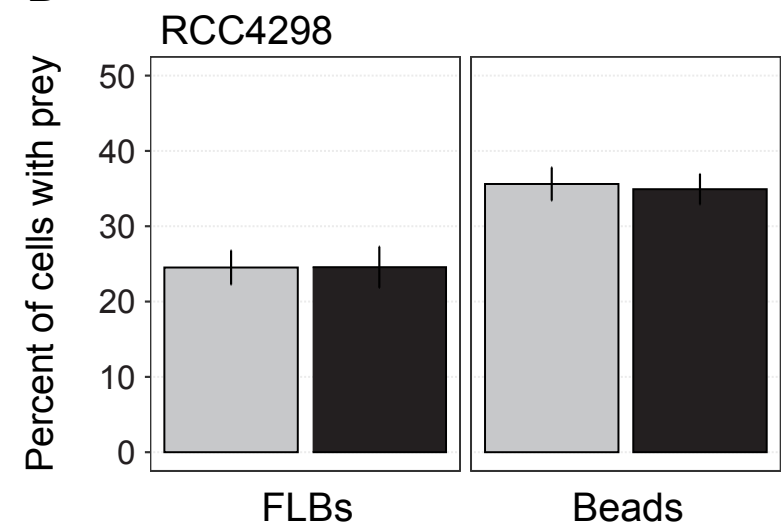

Feeding 2
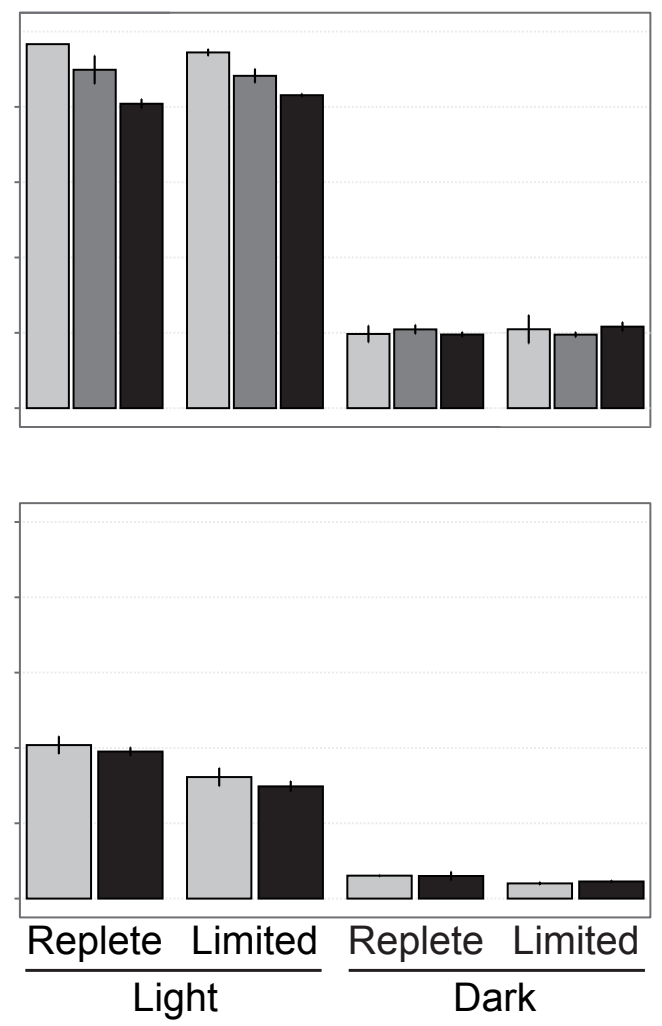

$\operatorname{RCC} 21$

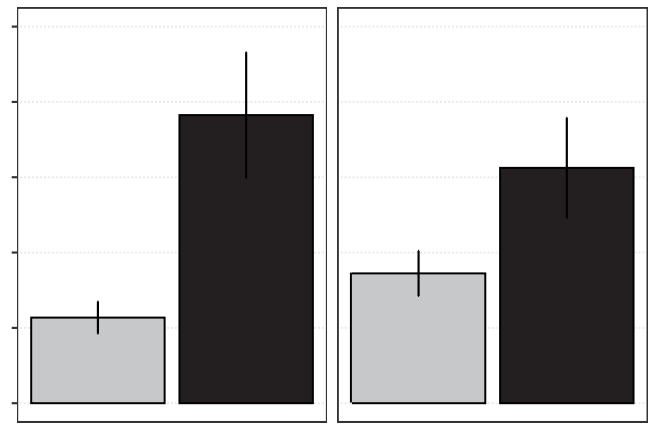

FLBs
Beads

Figure 2. A. Percent of $M$. polaris strains CCMP2009 and RCC4298 cells with YG-beads (M. polaris-EXP1) for different treatments. Two feeding experiments were performed. $B$. Percent of $M$. polaris strain RCC4298 and $O$. triangulata strain RCC21 cells with FLBs and YG-beads (EXP3). The color of the bars corresponds to the time after the addition of YG-beads (0 minutes; light grey, 20 minutes; dark grey, 40 minutes; black). Error bars correspond to standard deviation. 


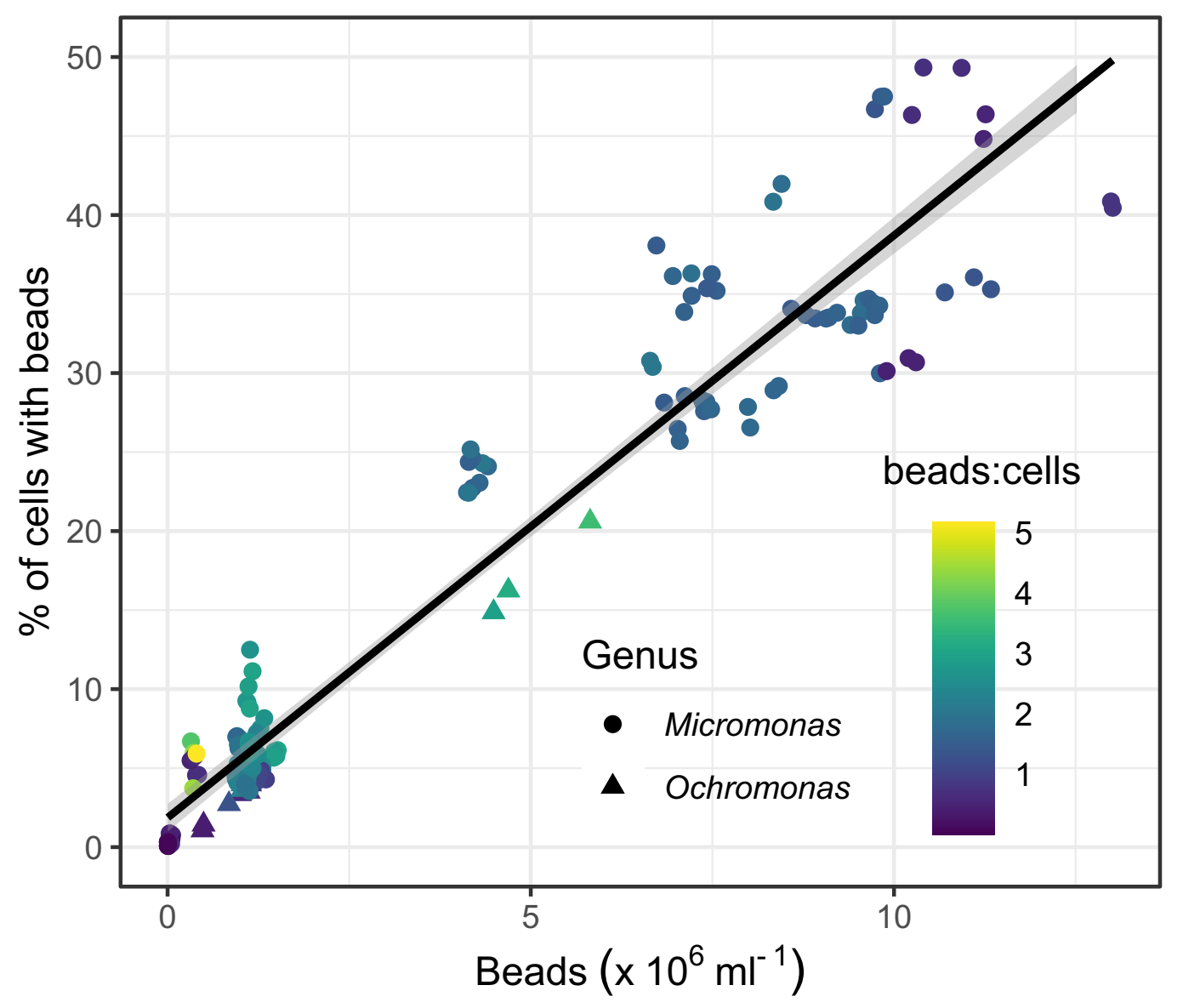

Figure 3. Relationship between percent of cells with YG-beads and bead concentration immediately after the addition of YG-beads $\left(T_{0}\right)$. The line and spread represents a fitted linear relationship $\left(R^{2}=0.93\right)$. Circles correspond to $M$. polaris and triangles to $O$. triangulata experiments. 

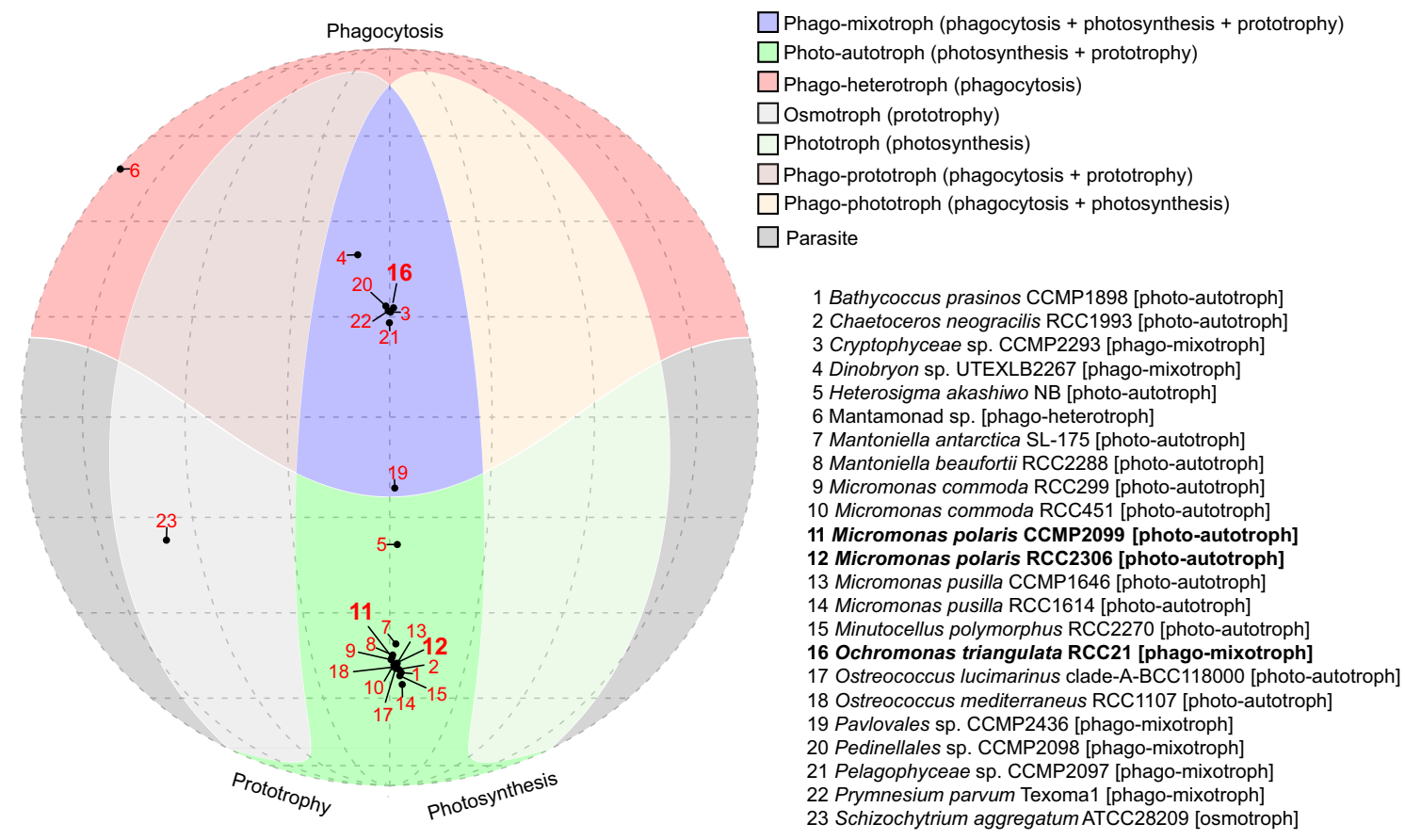

Figure 4. Trophic mode predictions from genome and transcriptome analysis. Predictions in three dimensions, phagocytosis, photosynthesis, and prototrophy were projected onto the circle. Shaded regions indicate regions where 0 (parasite, gray, lower edges) to all 3 (phago-mixotroph, blue, upper central region) predictions cross the positive threshold of $50 \%$ probability of a strain possessing a given function. Organisms positive for phagotrophy are in the upper hemisphere. Organisms positive for photosynthesis are in the middle to right region. Organisms positive for prototrophy are in the middle to left region. Organisms negative for all predictions are in the lower gray edge regions. Strains in bold correspond to those used in the feeding experiments. 


\section{Supplementary Material}

Table S1. List of strains used for transcriptome analysis. MMETSP corresponds to the Marine Microbial Eukaryote Transcriptome Sequencing Project (Keeling et al. 2014). METDB corresponds to the micro-eukaryotic marine species transcriptomes database available from http://metdb.sb-roscoff.fr/metdb/.

\begin{tabular}{|c|c|c|c|c|}
\hline Sequence Source & Species & Strain & Database & Reference \\
\hline Transcriptome & Bathycoccus prasinos & CCMP1898 & MMETSP & MMETSP1399 \\
\hline Transcriptome & Chaetoceros neogracilis & RCC1993 & MMETSP & MMETSP1336 \\
\hline Transcriptome & Cryptophyceae sp. & CCMP2293 & MMETSP & MMETSP0986-89 \\
\hline Transcriptome & Dinobryon sp. & UTEXLB2267 & MMETSP & MMETSP0019-20 \\
\hline Transcriptome & Dinobryon $s p$. & UTEXLB2267 & MMETSP & MMETSP0812 \\
\hline Transcriptome & Heterosigma akashiwo & NB & MMETSP & MMETSP0416 \\
\hline Transcriptome & Mantoniella antarctica & SL-175 & MMETSP & MMETSP1106 \\
\hline Transcriptome & Mantoniella beaufortii & RCC2288 & MMETSP & MMETSP1326 \\
\hline Genome & Micromonas commoda & RCC299 & NCBI & GCF_000090985.2 \\
\hline Transcriptome & Micromonas commoda & RCC451 & MMETSP & MMETSP1400 \\
\hline Transcriptome & Micromonas polaris & CCMP2099 & MMETSP & MMETSP0802 \\
\hline Transcriptome & Micromonas polaris & CCMP2099 & MMETSP & MMETSP1390 \\
\hline Transcriptome & Micromonas polaris & RCC2306 & MMETSP & MMETSP1327 \\
\hline Transcriptome & Micromonas pusilla & CCMP1646 & MMETSP & MMETSP1080 \\
\hline Transcriptome & Micromonas pusilla & RCC1614 & MMETSP & MMETSP1402 \\
\hline Transcriptome & Minutocellus polymorphus & RCC2270 & MMETSP & MMETSP1322 \\
\hline Transcriptome & Ochromonas triangulata & $\mathrm{RCC} 21$ & METDB & METDB-00278 \\
\hline Transcriptome & Ostreococcus lucimarinus & BCC118000 & MMETSP & MMETSP0939 \\
\hline Transcriptome & Ostreococcus mediterraneus & RCC1107 & MMETSP & MMETSP0938 \\
\hline Transcriptome & Pedinellales sp. & CCMP2098 & MMETSP & MMETSP0990-93 \\
\hline Transcriptome & Pelagophyceae sp. & CCMP2097 & MMETSP & MMETSP0974-77 \\
\hline Transcriptome & Pavlovales sp. & CCMP2436 & MMETSP & MMETSP0082-85 \\
\hline Transcriptome & Prymnesium parvum & Texoma1 & MMETSP & MMETSP0006-08 \\
\hline Transcriptome & Prymnesium parvum & Texoma1 & MMETSP & MMETSP0814-15 \\
\hline Transcriptome & Prymnesium parvum & Texoma1 & MMETSP & MMETSP1083 \\
\hline Transcriptome & Schizochytrium aggregatum & ATCC28209 & MMETSP & MMETSP0965 \\
\hline
\end{tabular}


Table S2. Summary of experimental conditions and results for all experiment performed with $M$. Polaris and $O$. triangulata strains. The percent of cells with prey (mean $\pm \mathbf{s d}$ ) is indicated for each time point after the addition of prey $\left(\mathbf{T}_{0}, \mathbf{T}_{20}\right.$ and $\mathbf{T}_{40}$, where the subscript corresponds to minutes). The last four columns correspond to Student and Welsh p-values.

\begin{tabular}{|c|c|c|c|c|c|c|c|c|c|c|c|c|c|c|c|}
\hline Species & strain & EXP type & Treatment & Prey & Feeding & Replication & Ratio prey to cells & $T_{0}$ & $\mathrm{~T}_{20}$ & $\mathrm{~T}_{40}$ & $\mathrm{~T}_{40}-\mathrm{T}_{0}$ & Student $\mathrm{T}_{0}$ vs. $\mathrm{T}_{20}$ & Welch $\mathrm{T}_{0}$ vS. $\mathrm{T}_{20}$ & Student $\mathrm{T}_{0}$ vS. $\mathrm{T}_{40}$ & Welch $T_{0}$ VS. $T_{40}$ \\
\hline Ochromonas triangulata & RCC21 & EXP1 & Light-replete & YG-beads & 1 & 2 & 0.6 & $4.0 \pm 0.1$ & $9.3 \pm 0.3$ & $12.3 \pm 0.3$ & 8.3 & 0.001 & 0.016 & 0.001 & 0.011 \\
\hline Ochromonas triangulata & $\mathrm{RCC} 21$ & EXP1 & Light-limited & YG-beads & 1 & 2 & 0.6 & $3.4 \pm 0.1$ & $7.6 \pm 0.0$ & $9.9 \pm 0.4$ & 6.5 & 0.000 & 0.011 & 0.002 & 0.016 \\
\hline Ochromonas triangulata & RCC21 & EXP2 & Light-replete & YG-beads & 1 & 2 & 13 & $33+0.8$ & & $9.4+22$ & 62 & & & 0.066 & 0.130 \\
\hline Ochromonas triangulata & RCC21 & EXP2 & Light-limited & YG-beads & 1 & 2 & 2.3 & $3.8 \pm 0.2$ & & $15.7 \pm 0.5$ & 11.9 & & & 0.001 & 0.006 \\
\hline Ochromonas triangulata & RCC21 & EXP3 & Light-replete & FLBs & 1 & 3 & 1.6 & $11.4 \pm 2.1$ & & $38.3 \pm 8.3$ & 26.9 & & & 0.006 & 0.025 \\
\hline Ochromonas triangulata & RCC21 & EXP3 & Light-replete & YG-Beads & 1 & 3 & 3.2 & $17.2 \pm 3.0$ & & $31.2 \pm 6.7$ & 14.0 & & & 0.029 & 0.050 \\
\hline Ochromonas triangulata & RCC21 & EXP4a & Light-replete & FLBs & 1 & 2 & 2.1 & $4.6 \pm 0.1$ & & $25.1 \pm 0.1$ & 20.5 & & & 0.000 & 0.000 \\
\hline Ochromonas triangulata & RCC21 & EXP4b & Light-replete & FLBs & 1 & 2 & 2.8 & $7.2 \pm 0.8$ & & $33.4 \pm 1.4$ & 26.2 & & & 0.002 & 0.006 \\
\hline Micromonas polaris & CCMP2099 & EXP1 & Dark-replete & YG-beads & 1 & 3 & 2.3 & $4.9 \pm 0.6$ & $4.1 \pm 0.3$ & $4.7 \pm 0.4$ & -0.2 & 0.134 & 0.154 & 0.707 & 0.710 \\
\hline Micromonas polaris & ССMP2099 & EXP1 & Dark-limited & YG-beads & 1 & 3 & 2.2 & $4.3 \pm 0.2$ & $3.5 \pm 0.6$ & $3.8 \pm 0.2$ & -0.5 & 0.092 & 0.126 & 0.044 & 0.047 \\
\hline Micromonas polaris & ССMP2099 & EXP1 & Light-replete & YG-beads & 1 & 3 & 1.7 & $32.7 \pm 6.1$ & $31.3 \pm 1.3$ & $33.3 \pm 0.4$ & 0.5 & 0.712 & 0.727 & 0.886 & 0.893 \\
\hline Micromonas polaris & CCMP2099 & EXP1 & Light-limited & YG-beads & 1 & 3 & 1.5 & $35.6 \pm 0.6$ & $30.8 \pm 0.3$ & $33.4 \pm 0.9$ & -2.2 & 0.000 & 0.001 & 0.024 & 0.032 \\
\hline Micromonas polaris & CCMP2099 & EXP1 & Dark-replete & YG-beads & 2 & 3 & 2.8 & $9.8 \pm 1.1$ & $10.5 \pm 0.6$ & $9.8 \pm 0.3$ & -0.1 & 0.451 & 0.464 & 0.922 & 0.925 \\
\hline Micromonas polaris & CCMP2099 & EXP1 & Dark-limited & YG-beads & 2 & 3 & 2.8 & $10.5 \pm 1.9$ & $9.8 \pm 0.3$ & $10.8 \pm 0.6$ & 0.3 & 0.551 & 0.579 & 0.775 & 0.784 \\
\hline Micromonas polaris & CCMP2099 & EXP1 & Light-replete & YG-beads & 2 & 3 & 0.7 & $48.3 \pm 1.7$ & $44.9 \pm 1.9$ & $40.4 \pm 0.6$ & -7.9 & 0.082 & 0.083 & 0.002 & 0.009 \\
\hline Micromonas polaris & ССMP2099 & EXP1 & Light-limited & YG-beads & 2 & 3 & 1.5 & $47.2 \pm 0.5$ & $44.1 \pm 0.9$ & $41.6 \pm 0.2$ & -5.7 & 0.007 & 0.015 & 0.000 & 0.000 \\
\hline Micromonas polaris & RCC2258 & EXP1 & Dark-replete & YG-beads & 1 & 3 & 2.1 & $4.5 \pm 0.2$ & $4.9 \pm 0.4$ & $\begin{array}{l}1.1 .000 .2 \\
4.5 \pm 0.5\end{array}$ & -0.0 & 0.242 & 0.255 & 0.899 & 0.901 \\
\hline Micromonas polaris & RCC2258 & EXP1 & Dark-limited & YG-beads & 1 & 3 & 2.0 & $3.8 \pm 0.2$ & $4.1 \pm 0.6$ & $4.1 \pm 0.3$ & 0.3 & 0.458 & 0.479 & 0.219 & 0.221 \\
\hline Micromonas polaris & RCC2258 & EXP1 & Light-replete & YG-beads & 1 & 3 & 1.6 & $34.0 \pm 0.9$ & $34.1 \pm 1.6$ & $33.1 \pm 2.3$ & -0.9 & 0.979 & 0.979 & 0.557 & 0.574 \\
\hline Micromonas polaris & RCC2258 & EXP1 & Light-limited & YG-beads & 1 & 3 & 1.6 & $32.6 \pm 2.3$ & $34.2 \pm 0.4$ & $32.0 \pm 2.1$ & -0.6 & 0.315 & 0.365 & 0.756 & 0.757 \\
\hline Micromonas polaris & RCC2258 & EXP1 & Dark-replete & YG-beads & 2 & 3 & 2.4 & $5.3 \pm 0.5$ & $4.9 \pm 0.9$ & $5.3 \pm 0.1$ & -0.1 & 0.499 & 0.513 & 0.849 & 0.816 \\
\hline Micromonas polaris & RCC2258 & $\begin{array}{l}\text { EXP1 } \\
\text { EXP1 }\end{array}$ & Dark-limited & $\begin{array}{l}\text { YG-beeas } \\
\text { YG-beads }\end{array}$ & 2 & 3 & 2.6 & $\begin{array}{l}5.3 \pm 0.5 \\
6.3 \pm 0.4\end{array}$ & $\begin{array}{l}4.9 \pm 0.9 \\
6.5 \pm 0.0\end{array}$ & $\begin{array}{l}5.3 \pm 0.1 \\
6.3 \pm 1.1\end{array}$ & $\begin{array}{l}-0.1 \\
-0.1\end{array}$ & 0.522 & 0.555 & $\begin{array}{l}0.949 \\
0.936\end{array}$ & $\begin{array}{l}0.938 \\
0.938\end{array}$ \\
\hline Micromonas polaris & RCC2258 & EXP1 & Light-replete & YG-beads & 2 & 3 & 0.5 & $30.6 \pm 0.4$ & $30.5 \pm 0.5$ & $29.8 \pm 0.3$ & -0.8 & 0.795 & 0.795 & 0.065 & 0.069 \\
\hline Micromonas polaris & RCC2258 & EXP1 & Light-limited & YG-beads & 2 & 3 & 1.4 & $35.5 \pm 0.5$ & $36.6 \pm 1.2$ & $33.8 \pm 2.4$ & -1.7 & 0.211 & 0.244 & 0.313 & 0.360 \\
\hline Micromonas polaris & RCC2306 & EXP1 & Dark-replete & YG-beads & 1 & 2 & $\begin{array}{l}2.4 \\
2.6\end{array}$ & $4.3 \pm 0.6$ & & $4.2 \pm 0.2$ & -0.1 & & & 0.853 & 0.865 \\
\hline Micromonas polaris & RCC2306 & EXP1 & Dark-limited & YG-beads & 1 & 2 & 2.5 & $4.6 \pm 0.0$ & & $3.7 \pm 0.2$ & $\begin{array}{l}-0.1 \\
-0.9\end{array}$ & & & 0.035 & 0.115 \\
\hline Micromonas polaris & RCC2306 & EXP1 & Light-replete & YG-beads & 1 & 2 & 1.7 & $29.0 \pm 0.2$ & & $29.0 \pm 0.1$ & -0.0 & & & 0.832 & 0.833 \\
\hline Micromonas polaris & RCC2306 & EXP1 & Light-limited & YG-beads & 1 & 2 & 1.7 & $27.2 \pm 0.9$ & & $27.7 \pm 0.3$ & 0.4 & & & 0.579 & 0.615 \\
\hline Micromonas polaris & RCC2306 & EXP1 & Dark-replete & YG-beads & 2 & 2 & 2.9 & $6.0 \pm 0.3$ & & $6.0 \pm 0.7$ & 0.1 & & & 0.883 & 0.891 \\
\hline Micromonas polaris & RCC2306 & EXP1 & Dark-limited & YG-beads & 2 & 2 & 2.9 & $5.9 \pm 0.3$ & & $5.5 \pm 0.2$ & -0.3 & & & 0.296 & 0.323 \\
\hline Micromonas polaris & RCC2306 & EXP1 & Light-replete & YG-beads & 2 & 2 & 0.5 & $45.6 \pm 1.1$ & & $46.5 \pm 0.1$ & 0.9 & & & 0.377 & 0.458 \\
\hline Micromonas polaris & RCC2306 & EXP1 & Light-limited & YG-beads & 2 & 2 & 0.8 & $40.7 \pm 0.3$ & & $40.5 \pm 0.2$ & -0.2 & & & 0.593 & 0.596 \\
\hline Micromonas polaris & RCC4298 & EXP1 & Dark-replete & YG-beads & 1 & 2 & 2.6 & $7.8 \pm 0.5$ & & $7.7 \pm 0.5$ & -0.2 & & & 0.740 & 0.740 \\
\hline Micromonas polaris & RCC4298 & EXP1 & Dark-limited & YG-beads & 1 & 2 & 2.3 & $7.1 \pm 0.2$ & & $6.8 \pm 0.1$ & -0.3 & & & 0.147 & 0.150 \\
\hline Micromonas polaris & RCC 4298 & EXP1 & Light-replete & YG-beads & 1 & 2 & 1.9 & $41.4 \pm 0.8$ & & $40.7 \pm 0.6$ & -0.7 & & & 0.429 & 0.433 \\
\hline Micromonas polaris & RCC4298 & EXP1 & Light-limited & YG-beads & 1 & 2 & 2.0 & $30.6 \pm 0.3$ & & $30.5 \pm 0.1$ & -0.1 & & & 0.598 & 0.618 \\
\hline Micromonas polaris & RCC 4298 & EXP1 & Dark-replete & YG-beads & 2 & 2 & 0.5 & $3.0 \pm 0.1$ & & $3.0 \pm 0.6$ & -0.0 & & & 0.928 & 0.935 \\
\hline Micromonas polaris & RCC4298 & EXP1 & Dark-limited & YG-beads & 2 & 2 & 0.5 & $2.0 \pm 0.2$ & & $2.3 \pm 0.2$ & 0.3 & & & 0.293 & 0.302 \\
\hline Micromonas polaris & RCC4298 & EXP1 & Light-replete & YG-beads & 2 & 2 & 0.2 & $20.4 \pm 1.2$ & & $19.5 \pm 0.6$ & -0.9 & & & 0.452 & 0.482 \\
\hline Micromonas polaris & RCC4298 & EXP1 & Light-limited & YG-beads & 2 & 2 & 0.2 & $16.1 \pm 1.2$ & & $14.9 \pm 0.7$ & -1.2 & & & 0.340 & 0.365 \\
\hline Micromonas polaris & RCC2258 & EXP2 & Dark-replete & YG-beads & 1 & 3 & 2.5 & $5.0 \pm 0.1$ & $4.7 \pm 0.1$ & $5.1 \pm 0.5$ & 0.1 & 0.046 & 0.053 & 0.826 & 0.834 \\
\hline Micromonas polaris & RCC2258 & EXP2 & Dark-limited & YG-beads & 1 & 3 & 2.2 & $4.4 \pm 0.1$ & $4.5 \pm 0.1$ & $4.3 \pm 0.1$ & -0.1 & 0.772 & 0.772 & 0.339 & 0.340 \\
\hline Micromonas polaris & RCC2258 & EXP2 & Light-replete & YG-beads & 1 & 3 & 1.6 & $33.6 \pm 0.2$ & $33.5 \pm 0.1$ & $33.2 \pm 0.1$ & -0.4 & 0.691 & 0.697 & 0.030 & 0.068 \\
\hline Micromonas polaris & RCC2258 & EXP2 & Light-replete-AntiB & YG-beads & 1 & 3 & 1.5 & $33.7 \pm 0.3$ & $34.2 \pm 0.3$ & $33.8 \pm 0.6$ & 0.1 & 0.112 & 0.113 & 0.881 & 0.883 \\
\hline Micromonas polaris & RCC2258 & EXP2 & Light-limited & YG-beads & 1 & 3 & 1.8 & $33.8 \pm 0.8$ & $33.6 \pm 0.2$ & $\begin{array}{l}33.00 .0 \\
33.1 \pm 0.1\end{array}$ & -0.7 & 0.673 & 0.689 & 0.208 & 0.270 \\
\hline Micromonas polaris & RCC2306 & EXP2 & Dark-replete & YG-beads & 1 & 3 & 2.1 & $4.6 \pm 0.2$ & $4.9 \pm 0.2$ & $4.6 \pm 0.2$ & 0.0 & 0.113 & 0.117 & 0.741 & 0.742 \\
\hline Micromonas polaris & RCC2306 & EXP2 & Dark-limited & YG-beads & 1 & 3 & 1.9 & $4.4 \pm 0.2$ & $3.9 \pm 0.4$ & $4.7 \pm 0.3$ & 0.3 & 0.172 & 0.190 & 0.279 & 0.290 \\
\hline Micromonas polaris & RCC2306 & EXP2 & Light-replete & YG-beads & 1 & 3 & 1.6 & $27.8 \pm 1.1$ & $28.8 \pm 0.4$ & $29.2 \pm 0.3$ & 1.4 & 0.213 & 0.253 & 0.099 & 0.151 \\
\hline Micromonas polaris & RCC2306 & EXP2 & Light-replete-AntiB & YG-beads & 1 & 3 & 1.6 & $27.8 \pm 0.3$ & $29.8 \pm 2.5$ & $28.7 \pm 0.5$ & 0.9 & 0.235 & 0.294 & 0.068 & 0.086 \\
\hline Micromonas polaris & RCC2306 & EXP2 & Light-limited & YG-beads & 1 & 3 & $\begin{array}{l}1.6 \\
1.6\end{array}$ & $28.0 \pm 0.2$ & $28.0 \pm 0.1$ & $27.9 \pm 0.1$ & $\begin{array}{c}-0.1 \\
-0.1\end{array}$ & 0.782 & 0.785 & 0.551 & 0.557 \\
\hline Micromonas polaris & RCC4298 & EXP3 & Light-replete & FLBs & 1 & 3 & 1.8 & $24.5 \pm 2.3$ & & $24.6 \pm 2.7$ & 0.0 & & & 0.984 & 0.984 \\
\hline Micromonas polaris & RCC4298 & EXP3 & Light-replete & YG-beads & 1 & 3 & 1.6 & $35.6 \pm 2.2$ & & $34.9 \pm 2.0$ & -0.7 & & & 0.709 & 0.709 \\
\hline Micromonas polaris & RCC2306 & EXP5 & Dark-replete & YG-beads & 1 & 2 & 1.1 & $4.4 \pm 0.3$ & & & & & & & \\
\hline Micromonas polaris & RCC2306 & EXP5 & Light-replete & YG-beads & 1 & 2 & 0.9 & $4.6 \pm 0.4$ & & & & & & & \\
\hline Micromonas polaris & RCC2306 & EXP5 & Light-replete & YG-beads & 1 & 2 & 0.7 & $4.6 \pm 0.0$ & & & & & & & \\
\hline Micromonas polaris & RCC2306 & EXP5 & Light-replete & YG-beads & 1 & 2 & 0.1 & $0.4 \pm 0.1$ & & & & & & & \\
\hline Micromonas polaris & RCC2306 & EXP5 & Light-replete & YG-beads & 1 & 2 & 0.0 & $0.1 \pm 0.0$ & & & & & & & \\
\hline Micromonas polaris & RCC2306 & EXP5 & Light-replete & YG-beads & 1 & 2 & 4.0 & $6.3 \pm 0.5$ & & & & & & & \\
\hline Micromonas polaris & RCC2306 & EXP5 & Light-replete & YG-beads & 1 & 2 & 0.6 & $0.8 \pm 0.1$ & & & & & & & \\
\hline Micromonas polaris & RCC2306 & EXP5 & Light-replete & YG-beads & 1 & 2 & 0.1 & $0.2 \pm 0.2$ & & & & & & & \\
\hline Micromonas polaris & RCC2306 & EXP5 & Light-replete & YG-beads & 1 & 2 & 1.3 & $4.4 \pm 0.2$ & & & & & & & \\
\hline Micromonas polaris & RCC2306 & & & $\begin{array}{l}\text { S-beads } \\
\text { S-beads }\end{array}$ & 1 & 2 & 1.3 & $4.4 \pm 0.1$ & & & & & & & \\
\hline Micromonas polaris & RCC4298 & & & ds & 1 & 2 & 0 & 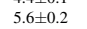 & & & & & & & \\
\hline Micromonas polaris & $\mathrm{RC}$ & & Light-replete & YG-beads & 1 & 2 & 0.1 & $0.5 \pm 0.2$ & & & & & & & \\
\hline Micromonas polaris & RCC4298 & EXP5 & Light-replete & YG-beads & 1 & 2 & 0.0 & $0.1 \pm 0.0$ & & & & & & & \\
\hline Micromonas polaris & RCC4298 & EXP5 & Light-replete & YG-beads & 1 & 2 & 4.8 & $4.8 \pm 1.5$ & & & & & & & \\
\hline Micromonas polaris & RCC4298 & EXP5 & Light-replete & YG-beads & 1 & 2 & 0.5 & $0.5 \pm 0.5$ & & & & & & & \\
\hline Micromonas polaris & RCC4298 & EXP5 & Light-replete & YG-beads & 1 & 2 & 0.1 & $0.2 \pm 0.2$ & & & & & & & \\
\hline Micromonas polaris & RCC4298 & EXP5 & Dark-replete & YG-beads & 1 & 3 & 1.8 & $7.0 \pm 0.1$ & & & & & & & \\
\hline Micromonas polaris & RCC4298 & EXP5 & Dark-limited & YG-beads & 1 & 3 & 1.9 & $6.4 \pm 0.2$ & & & & & & & \\
\hline polaris & RCC4298 & EXP & & YG-beads & 1 & 3 & 1.7 & $24.7 \pm 0.4$ & & & & & & & \\
\hline$M$ & & & -AntiB & & 1 & 3 & 1. & & & & & & & & \\
\hline Micromonas polaris & RCC 4298 & EXP5 & Light-limited & YG-beads & 1 & 3 & 1.8 & $22.5 \pm 0.2$ & & & & & & & \\
\hline
\end{tabular}


Table S3. Comparison of feeding on three different YG-bead sizes (diamter 0.5, 1, and $2 \mu \mathrm{m})$ for M. polaris (EXP7). The percent of cells with prey (mean \pm sd) was measured independently for each bead size and is indicated for each time point $\left(T_{0}\right.$ and $T_{40}$, where the subscript correspond to minutes).

\begin{tabular}{|c|c|c|c|c|c|c|c|c|}
\hline Species & strain & Treatment & Prey & Replication & Prey/cell ratio & $\mathrm{T}_{0}$ & $\mathrm{~T}_{40}$ & $\mathrm{~T}_{40}-\mathrm{T}_{0}$ \\
\hline Micromonas polaris & RCC2306 & Light-limited & YG-beads $0.5 \mu \mathrm{m}$ & 2 & 1.0 & $4.09 \pm 0.32$ & $4.08 \pm 0.07$ & 0.0 \\
\hline Micromonas polaris & RCC2306 & Light-limited & YG-beads $1.0 \mu \mathrm{m}$ & 2 & 0.9 & $3.27 \pm 0.14$ & $2.30 \pm 0.10$ & -1.0 \\
\hline Micromonas polaris & RCC2306 & Light-limited & YG-beads $2.0 \mu \mathrm{m}$ & 2 & 0.7 & $3.54 \pm 0.03$ & $2.74 \pm 0.05$ & -0.8 \\
\hline
\end{tabular}

Table S4. Comparison of Lugol's iodine and glutaraldehyde fixation, and live (no fixation) measurements of the percent of $M$. polaris cells with YG-beads (EXP6). The percent of cells with prey (mean \pm sd) is indicated for each time point after the addition of prey $\left(\mathbf{T}_{0}\right.$ and $\mathbf{T}_{40}$, where the subscript corresponds to minutes).

\begin{tabular}{cccccccccc}
\hline Species & strain & Treatment & Prey & Fixation & Replication & Prey/cell ratio & $\mathrm{T}_{0}$ & $\mathrm{~T}_{40}$ & $\mathrm{~T}_{40}-\mathrm{T}_{0}$ \\
\hline Micromonas polaris & RCC2306 & Light-replete & YG-beads & No (Live) & 2 & 1.6 & $7.57 \pm 0.60$ & $7.20 \pm 0.28$ & -0.4 \\
Micromonas polaris & RCC2306 & Light-replete & YG-beads & Lugol's iodine & 2 & 1.4 & $5.85 \pm 0.39$ & $5.58 \pm 0.18$ & -0.3 \\
Micromonas polaris & RCC2306 & Light-replete & YG-beads & Glutaraldehyde & 2 & 1.5 & $6.97 \pm 0.39$ & $6.62 \pm 0.01$ & -0.3 \\
\hline
\end{tabular}

Table S5. Lysosensor experiment (EXP9). Last column shows the mean \pm sd Lysosensor green.

\begin{tabular}{llcccc}
\hline Species & strain & treatment & Unstained or Stained & Replication & Green fluorescence \\
\hline Ochromonas triangulata & RCC21 & Light-limited & Unstained & 2 & $64.0 \pm 1.1$ \\
Ochromonas triangulata & RCC21 & Light-limited & Stained & 2 & $221.5 \pm 40.5$ \\
Micromonas polaris & RCC2306 & Light-limited & Unstained & 2 & $56.7 \pm 2.4$ \\
Micromonas polaris & RCC2306 & Light-limited & Stained & 2 & $67.8 \pm 1.9$ \\
\hline
\end{tabular}


Red-Threshold
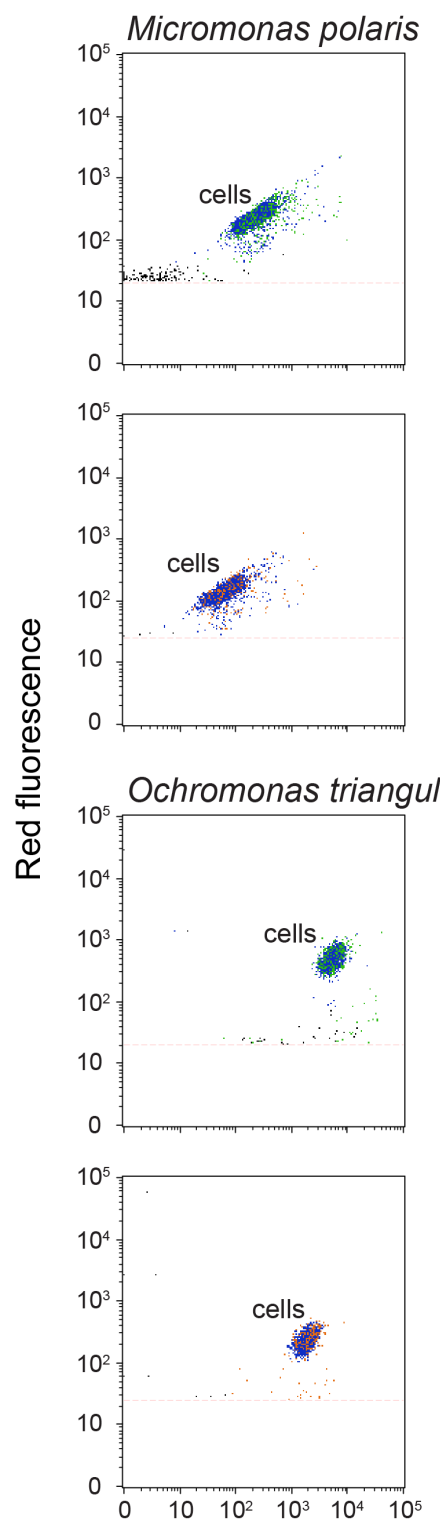

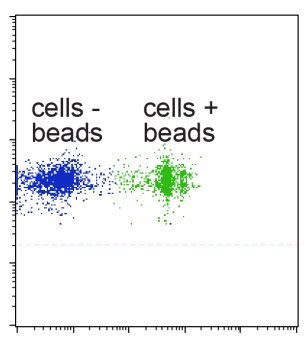

Green-Threshold
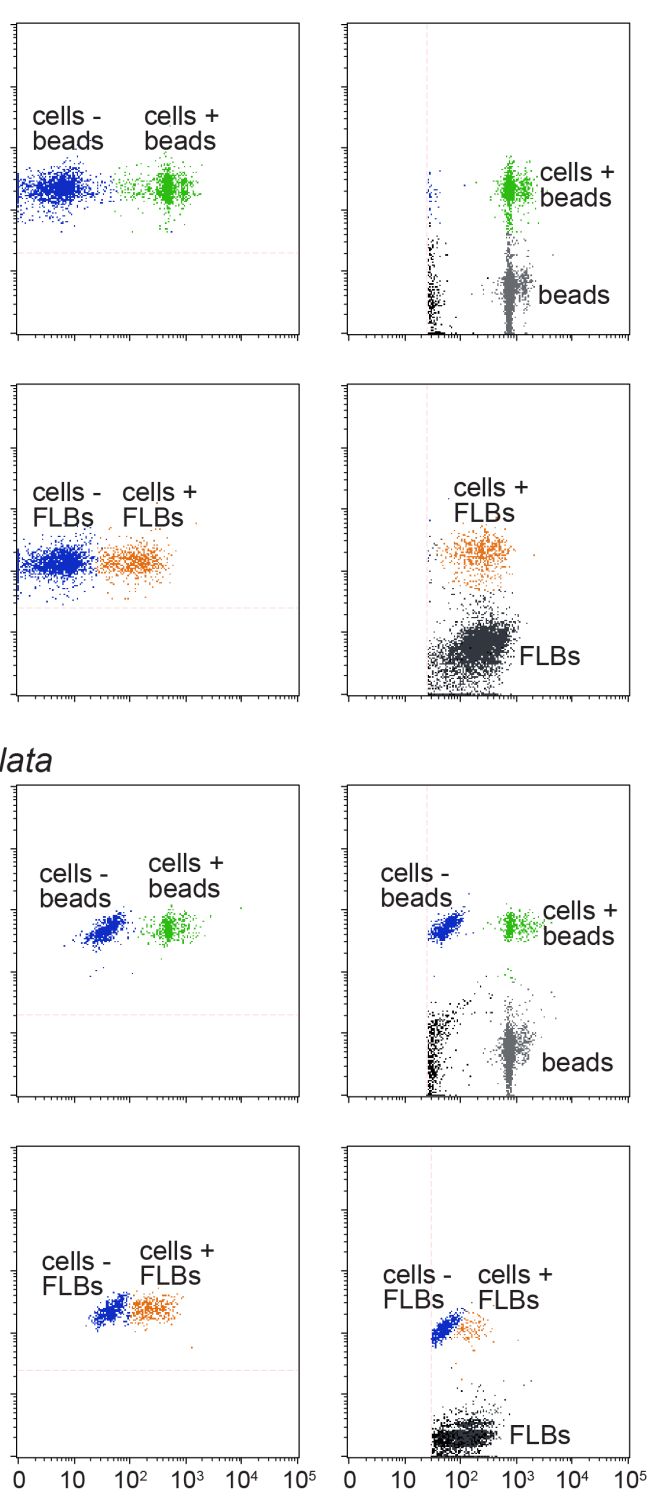

Green fluorescence

Figure S1. Examples of flow cytograms for $M$. polaris and the positive control $O$. triangulata. Flow cytometry was used to determine the percent of cells with prey (YG-beads and FLBs) in fixed samples using a protocol modified from Sherr \& Sherr (1993). Data collection was performed with threshold on red $(695 \pm 50 \mathrm{~nm}$ band pass filter) or green fluorescence (525 $\pm 30 \mathrm{~nm}$ band pass filter). Cells that displayed red autofluorescence from chlorophyll as well as green fluorescence were considered to be containing prey (cells with YG-beads in green, cells with FLBs in orange and cells without prey in blue). In addition, to confirm the total concentration of prey added to each experimental flask, the same sample was also run with the threshold on green fluorescence (YG-beads and FLBs in grey and black respectively). 

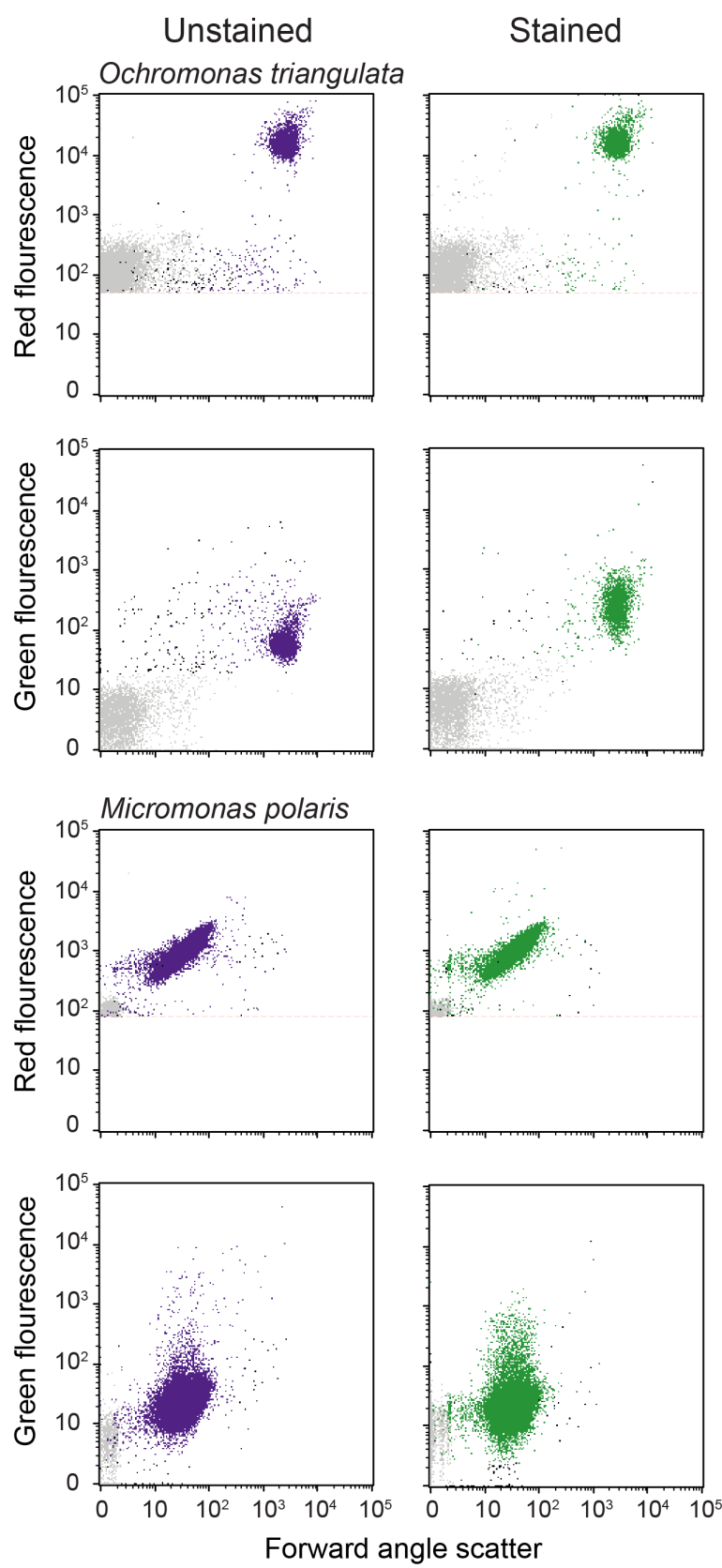

Figure S2. Flow cytograms of $O$. triangulata and $M$. polaris before (purple) and after (green) staining with Lysosensor. Red fluorescence corresponds to chlorophyll fluorescence, while green fluorescence corresponds to autofluorescence before staining or to Lysosensor fluorescence after staining. Green fluorescence clearly increases after Lysosensor staining for $O$. triangulata and not for $M$. polaris. 

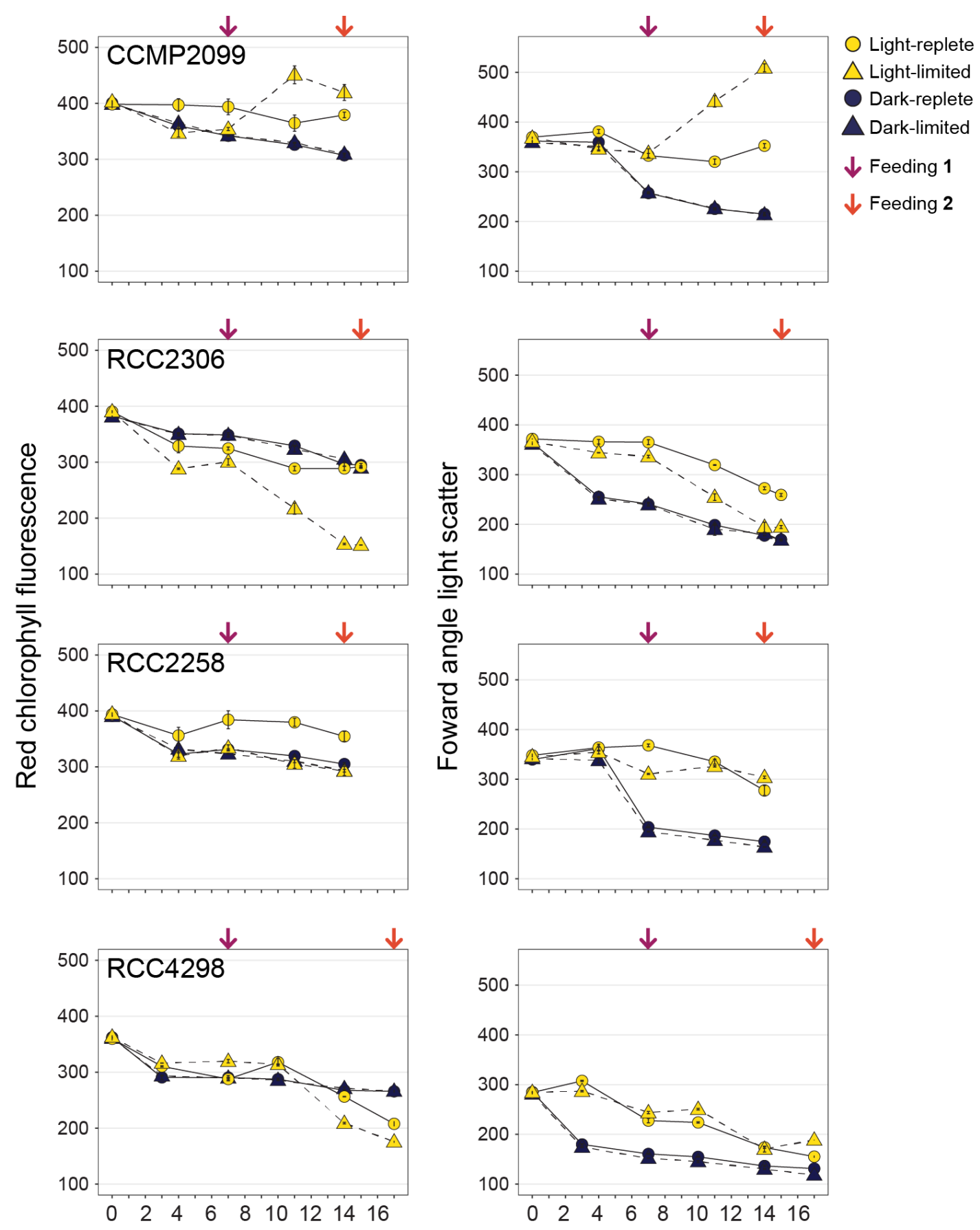

Time (days)

Figure S3. Change in forward scatter and red chlorophyll fluorescence measured by flow cytometry during the experiments reported in Figure 1 (M. polaris-EXP1). 


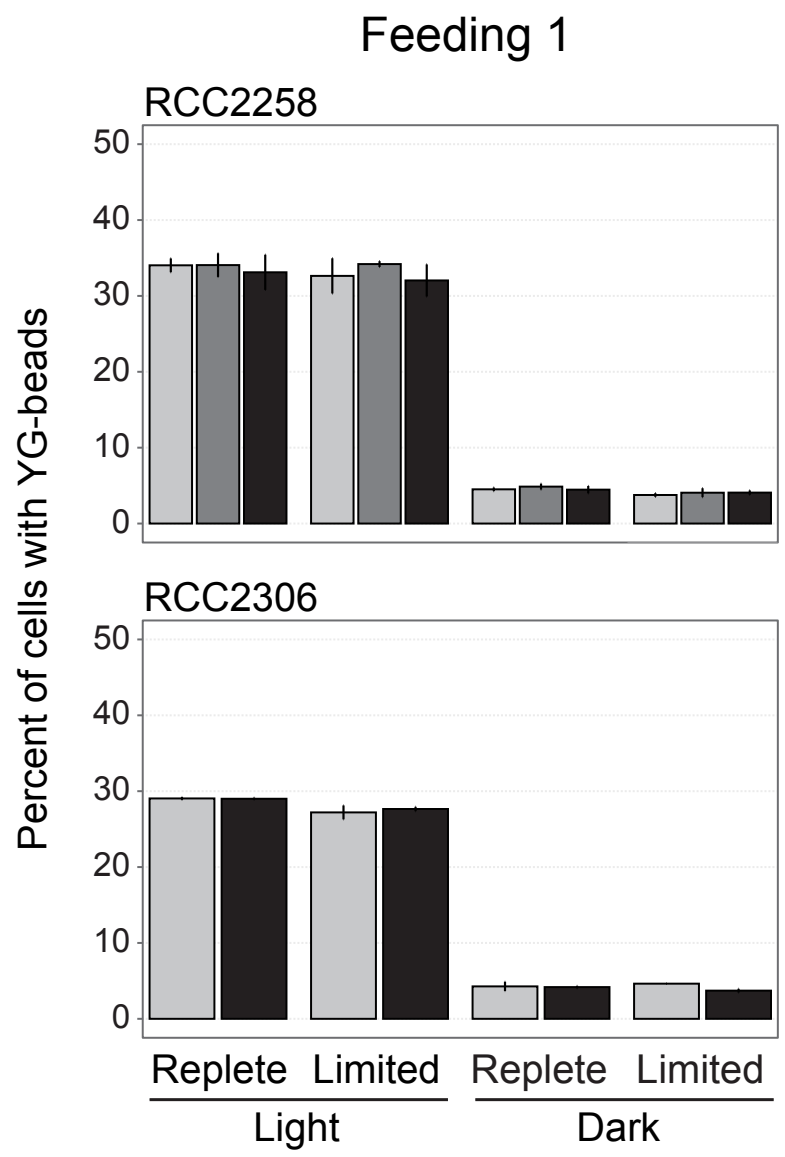

Feeding 2
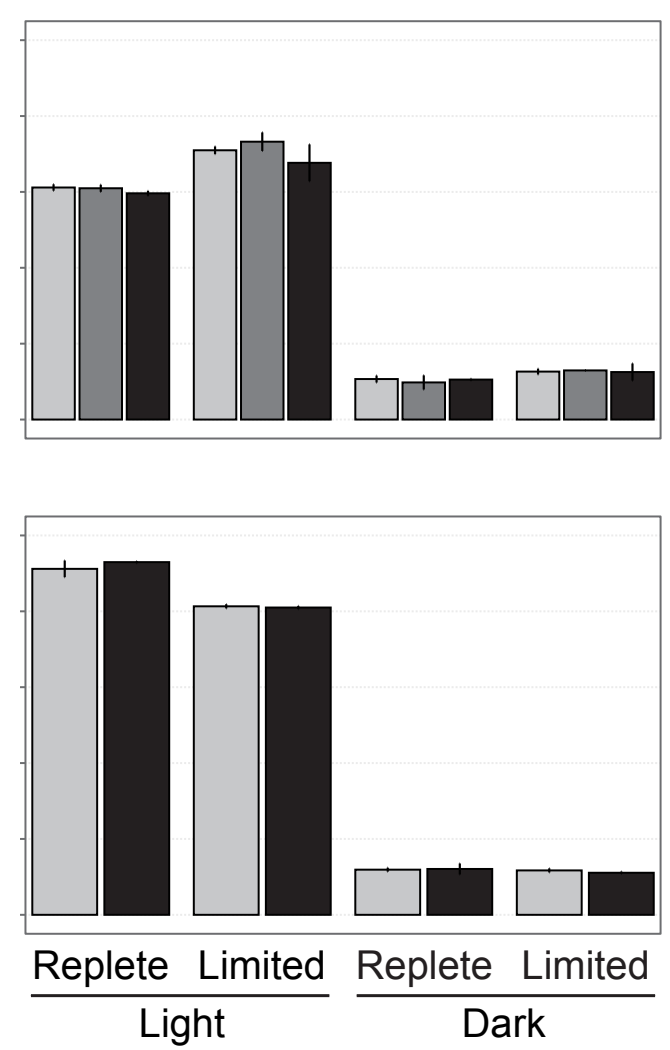

Figure S4. Percent of $M$. polaris cells with YG-beads (M. polaris-EXP1) for strains RCC2258 and RCC2306 and different treatments. Two feeding experiments were performed. The color of the bars represent the time point (in minutes) after the addition of YG-beads (0 minutes; light grey, 20 minutes; dark grey, 40 minutes; black). Error bars correspond to standard deviation. 


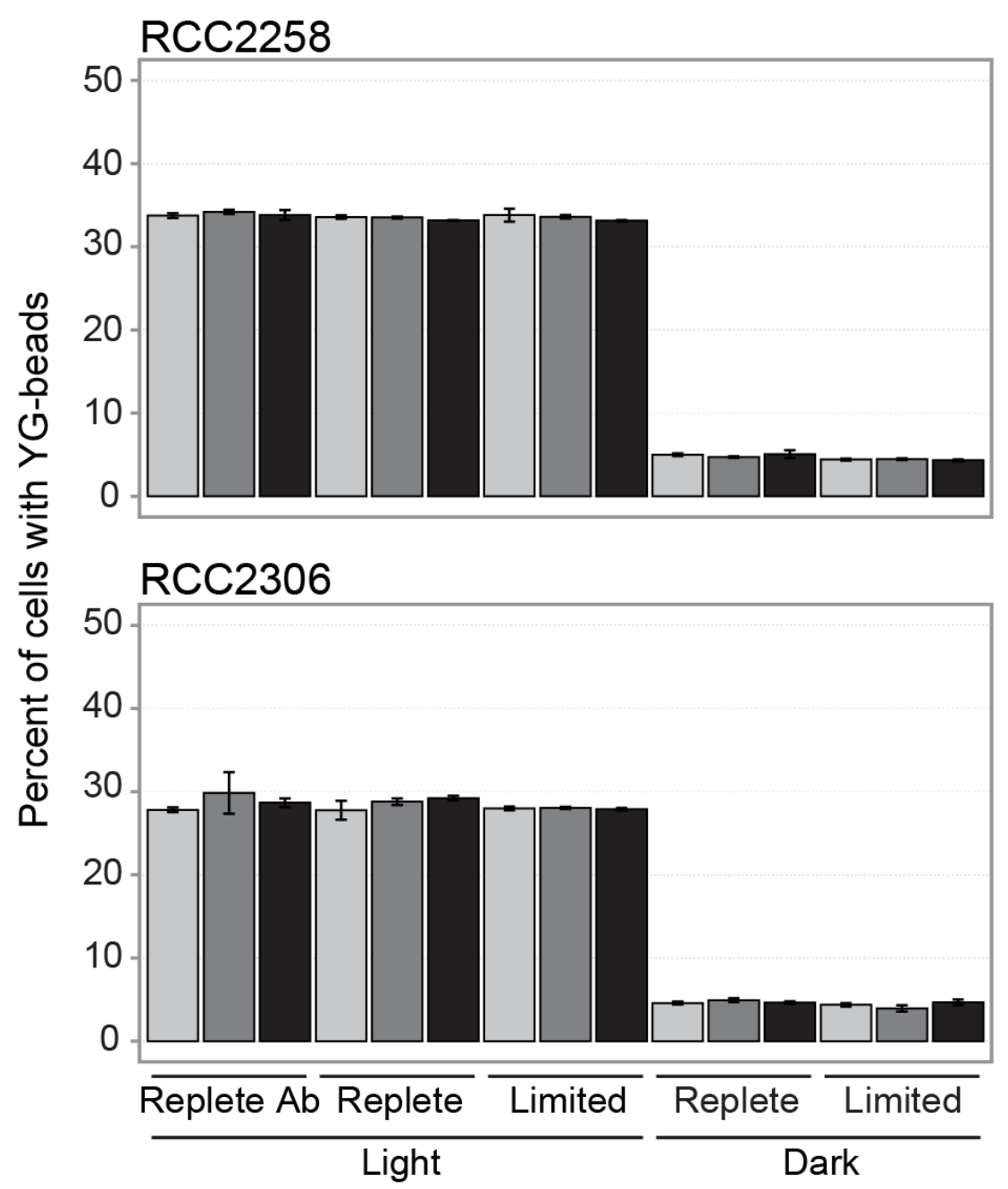

Figure S5. Percent of M. polaris cells with YG-beads (M. polaris-EXP2) for each strain and treatment. The color of the bars represents the time point (in minutes) after the addition of YG-beads ( 0 minutes; light grey, 20 minutes; dark grey, 40 minutes; black). Replete $\mathrm{Ab}$ correspond to nutrient replete conditions with antibiotics. 


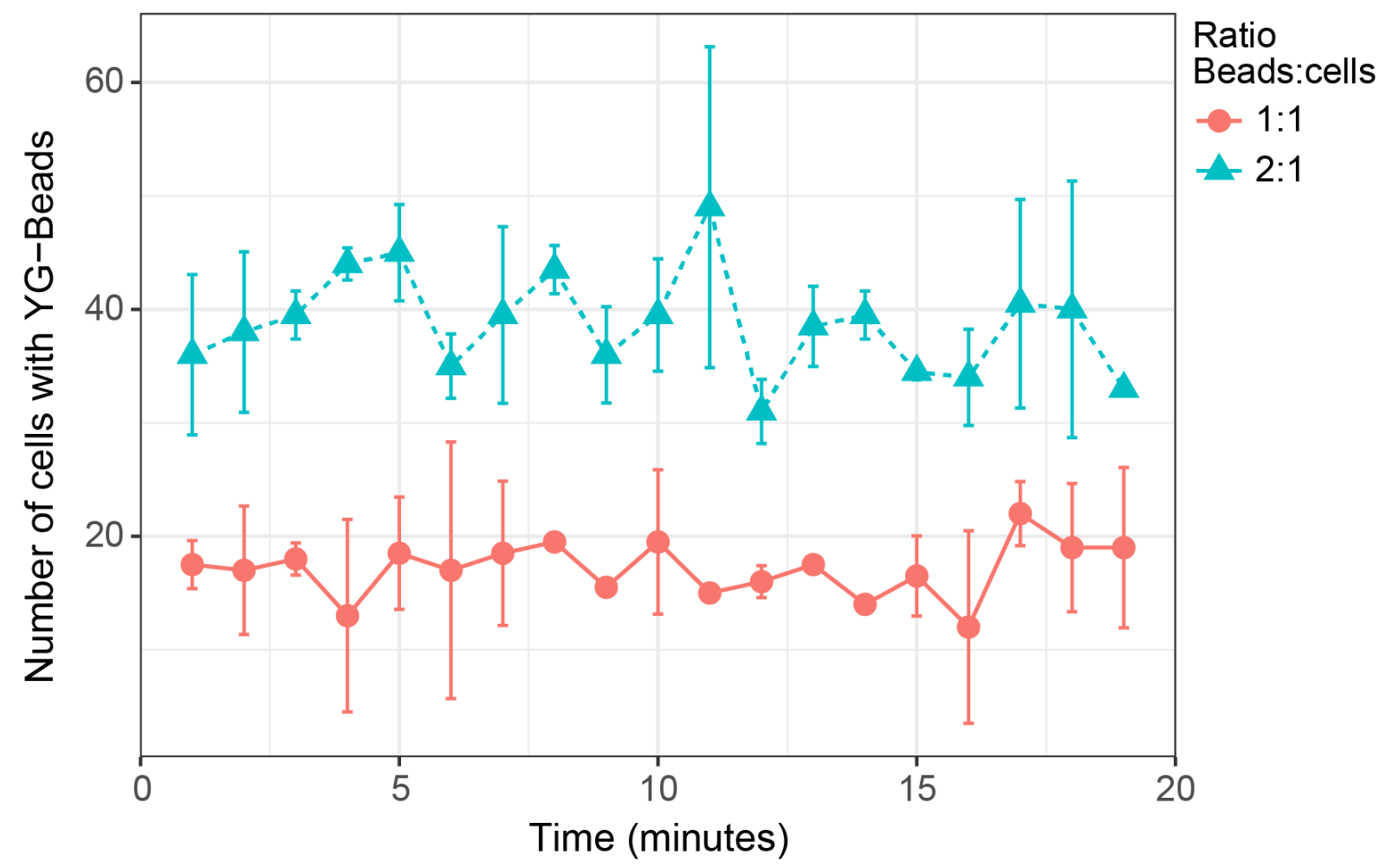

Figure S6. Changes with time in the number of $M$. polaris (strain RCC2306) cells with YG-beads measured by continuously running a live sample for 20 minutes immediately after the addition of YG-beads. Two ratios of beads to cells were tested, 1:1 and 2:1, each in duplicate. 

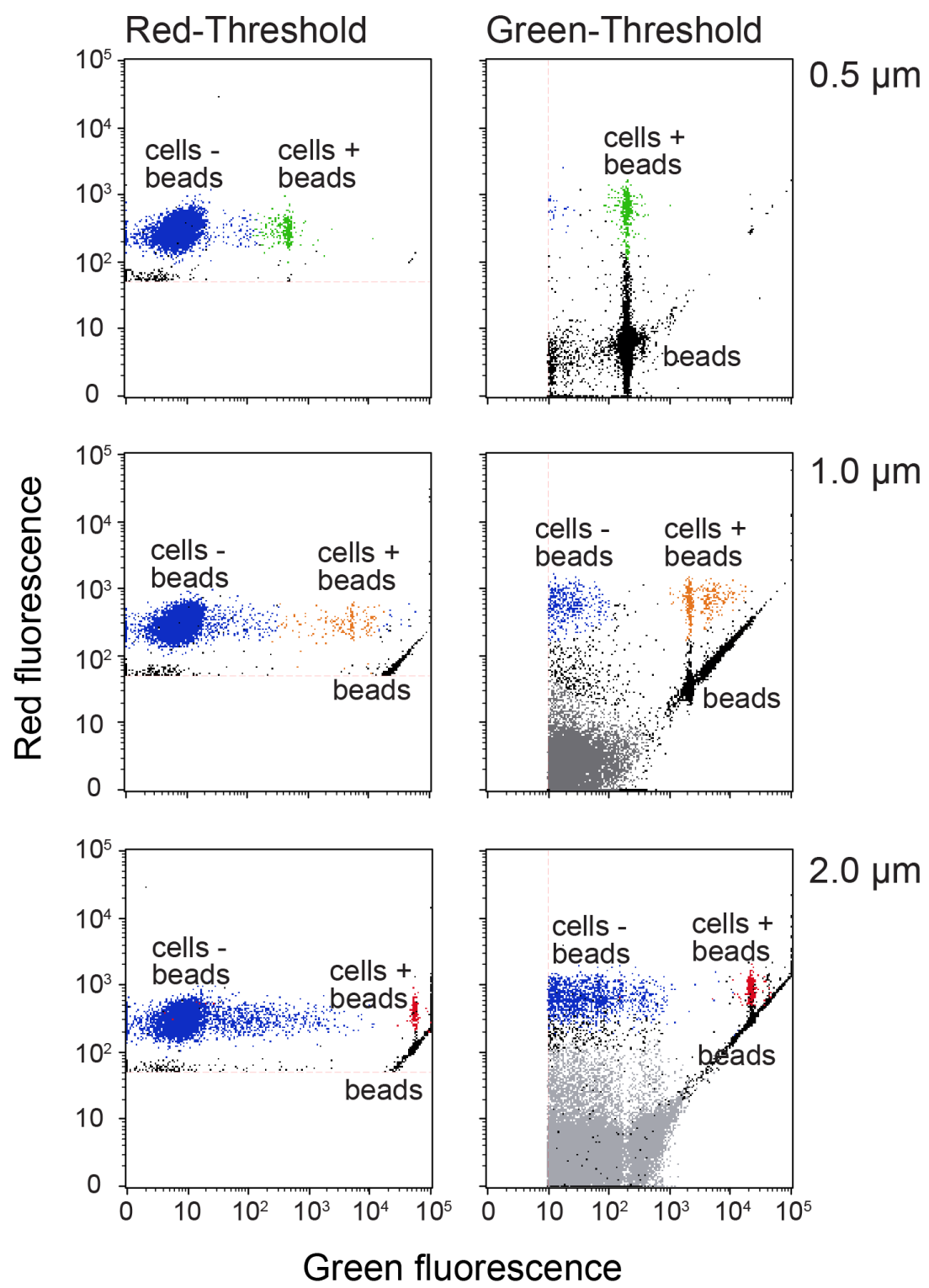

Figure S7. Flow cytograms for M. polaris cells incubated with YG-beads of three different sizes: 0.5 (green), 1.0 (orange) and 2.0 (red) $\mu \mathrm{m}$. See legend of Figure S1 for details. 

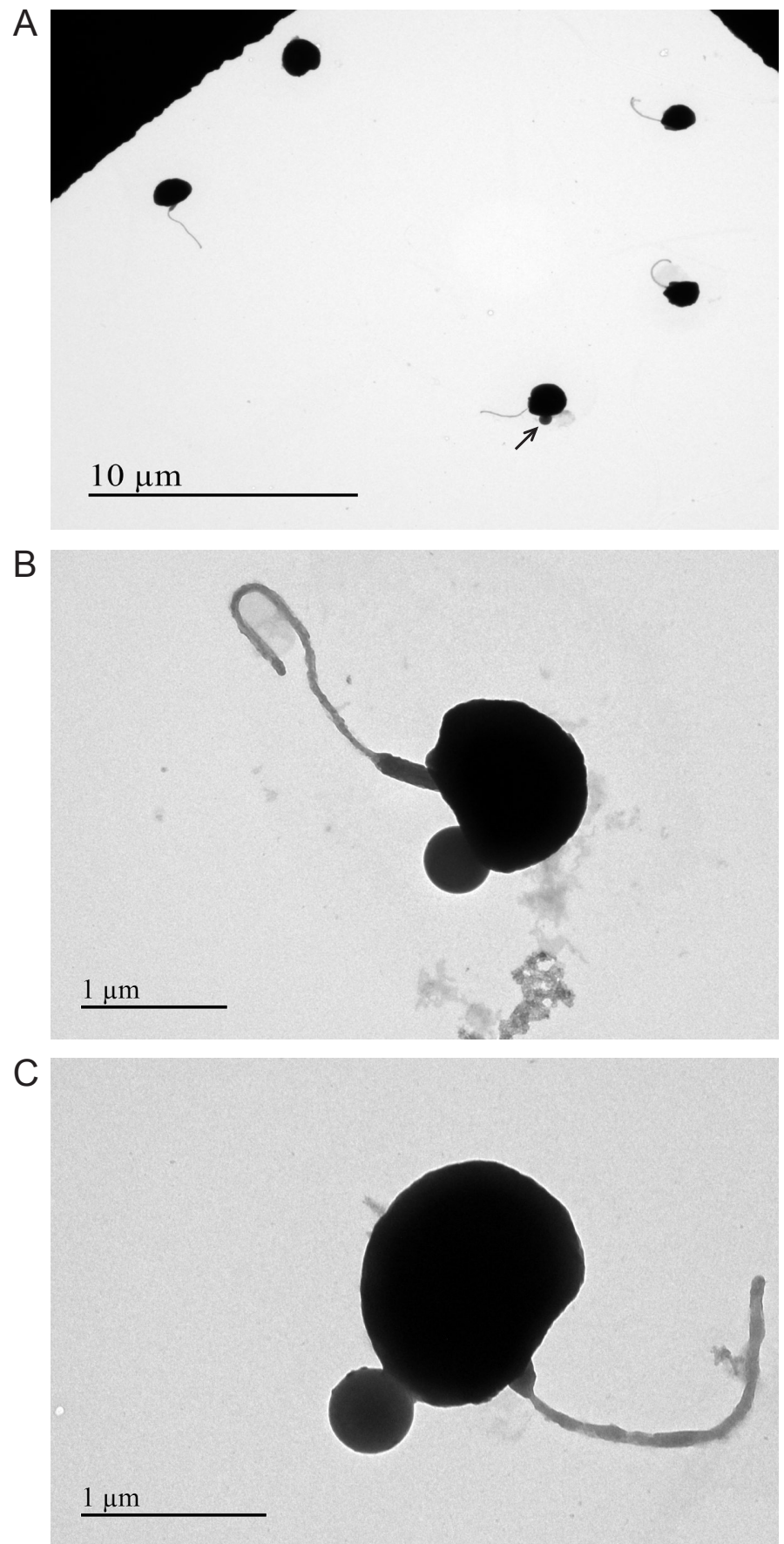

Figure S8. Transmission electron microscopy images of $M$. polaris (strain RCC2306) with YG-beads $(0.5 \mu \mathrm{m})$ after negative staining. A. Arrow indicates a $M$. polaris cell with a YG-bead. B and C. Close up views of $M$. polaris cells with attached YG-bead. 